\title{
Cryptic role of tetrathionate in the sulfur cycle: A study from Arabian Sea oxygen minimum zone sediments
}

Subhrangshu Mandal ${ }^{1}$, Sabyasachi Bhattacharya ${ }^{1}$, Chayan Roy ${ }^{1}$, Moidu Jameela Rameez ${ }^{1}$, 5 Jagannath Sarkar ${ }^{1}$, Svetlana Fernandes ${ }^{2}$, Tarunendu Mapder ${ }^{3}$, Aditya Peketi ${ }^{2}$, Aninda Mazumdar2,* and Wriddhiman Ghosh ${ }^{1, *}$

1 Department of Microbiology, Bose Institute, P-1/12 CIT Scheme VIIM, Kolkata 700054, India.

2 CSIR-National Institute of Oceanography, Dona Paula, Goa 403004, India.

103 ARC CoE for Mathematical and Statistical Frontiers, School of Mathematical Sciences, Queensland University of Technology, Brisbane, QLD 4000, Australia.

* Correspondence emails: Running Title: wriman@jcbose.ac.in / maninda@nio.org

Tetrathionate metabolism in marine sediments

KEYWORDS: sulfur cycle, tetrathionate, marine oxygen minimum zone, sediment biogeochemistry

ABSTRACT To explore the potential role of tetrathionate in the sulfur cycle of marine sediments, the population ecology of tetrathionate-forming, oxidizing, and respiring microorganisms was revealed at 15$30 \mathrm{~cm}$ resolution along two, $\sim 3-\mathrm{m}$-long, cores collected from 530- and 580-mbsl water-depths of Arabian Sea, off India's west coast, within the oxygen minimum zone (OMZ). Metagenome analysis along the two sediment-cores revealed widespread occurrence of the structural genes that govern these metabolisms; high diversity and relative-abundance was also detected for the bacteria known to render these processes. Slurry-incubation of the sediment-samples, pure-culture isolation, and metatranscriptome analysis, corroborated the in situ functionality of all the three metabolic-types. Geochemical analyses revealed thiosulfate $(0-11.1 \mu \mathrm{M})$, pyrite (0.05-1.09 wt \%), iron (9232-17234 ppm) and manganese (71-172 ppm) along the two sediment-cores. Pyrites (via abiotic reaction with $\mathrm{MnO}_{2}$ ) and thiosulfate (via oxidation by chemolithotrophic bacteria prevalent in situ) are apparently the main sources of tetrathionate in this ecosystem. Tetrathionate, in turn, can be either converted to sulfate (via oxidation by the chemolithotrophs present) or reduced back to thiosulfate (via respiration by native bacteria); 0-2.01 mM sulfide present in the sediment-cores may also reduce tetrathionate abiotically to thiosulfate and elemental sulfur. Notably tetrathionate was not detected in situ - high microbiological and geochemical reactivity of this polythionate is apparently instrumental in the cryptic nature of its potential role as a central sulfur cycle intermediate. Biogeochemical roles of this polythionate, albeit revealed here in the context of OMZ sediments, may well extend to the sulfur cycles of other geomicrobiologically-distinct marine sediment horizons.

\section{Introduction}

Phylogenetically diverse microorganisms oxidize and/or reduce different sulfur species to meet their bioenergetic requirements, and in doing so play profound roles in running biogeochemical 45 sulfur cycles in nature (Baumgartner et al., 2006; Ghosh and Dam, 2009). Within the marine realm, microbial processes of sulfur cycle are central to benthic biogeochemistry as they are 
linked to the in situ transformations, sequestrations, and fluxes of carbon and iron. So there have been extensive studies of benthic/sedimentary sulfur cycle across the global ocean (Jørgensen, 1990; Jørgensen and Bak 1991; Rudnicki et al., 2001; Tostevin et al., 2014), and focus has 50 typically been on geomicrobial transformations of the two end-members sulfate and sulfide (Holmkvist et al., 2011), and also thiosulfate which constitutes a key junction in the network of sulfur species transformation in marine sediments (Jørgensen, 1990; Jørgensen and Bak 1991 Thamdrup et al., 1994). In this context, however, tetrathionate or other polythionates are seldom appreciated for their potential role(s) in marine sedimentary sulfur cycle, presumably because

55 these sulfur species are not abundant in these environments. Overall paucity of polythionates in any environment is largely attributable to their high reactivity under biotic (Kanao et al., 2007; Ghosh and Dam, 2009; Boden et al., 2010; Pyne et al., 2017, 2018) as well as abiotic (Schippers et al., 1999; Schippers and Jørgensen, 2001) conditions. Cryptic nature of these sulfur species notwithstanding, several bacteria capable of producing and/or utilizing tetrathionate for 60 bioenergetic purposes have been isolated from different terrestrial and aquatic (both fresh-water and marine) habitats (Kaprálek, 1972; Oltmann and Stouthamer, 1975; Barrett and Clark, 1987; Sass et al., 1992; Price-Carter et al., 2001; Sorokin, 2003; Ghosh et al., 2005; Ghosh et al., 2006; Ghosh and Roy, 2007; Ghosh and Dam, 2009). Here we investigate the potential involvement of tetrathionate in the sulfur cycle of a marine sediment horizon located within the 65 perennial oxygen minimum zone $(\mathrm{OMZ})$ of the eastern Arabian Sea, off the west coast of India. Community structures and functions of tetrathionate-forming, oxidizing, and respiring, microorganisms were revealed (via metagenomics, metatranscriptomics and pure-culture isolation) along two 3-m-long sediment cores (Fernandes et al., 2018) collected from 530 and 580 meters below the sea level ( $\mathrm{mbsl}$ ); the microbial ecology was then considered in the context 70 of the in situ geochemistry, and implications were inferred for the in situ sulfur cycle.

\section{Materials and methods}

\subsection{Sample collection and storage}

The gravity cores SSK42/5 and 6 were sampled, as described previously, under constant shower

75 of high-purity $\mathrm{N}_{2}$ to avoid aerial oxidation of the $\mathrm{H}_{2} \mathrm{~S}$ and $\mathrm{Fe}^{2+}$ potentially present in the sediments (Fernandes et al., 2018). Immediately after the longitudinal halves of the PVC core-liners were cut open, top one $\mathrm{cm}$ of the exposed surfaces of the individual cores were scrapped off using sterile scalpels to eliminate potential contaminations from the core-liners' inner-surfaces and/or sea-waters through which the cores had passed (Fernandes et al., 2018). Sample bottles were 80 flushed with high-purity $\mathrm{N}_{2}$ before they were screw-capped, sealed with Parafilm (Bemis Company Inc., Neenah, WI, USA), and refrigerated. For every sediment-sample, two fractions designated for duplicate metagenome analysis were put into $-20^{\circ} \mathrm{C}$ freezers, while one fraction 
each for chemistry and culture-based microbiological studies were kept at $4^{\circ} \mathrm{C}$. These temperatures were all the time maintained during transfer of the samples to the institutes, and 85 also over their long-term preservation in the laboratories.

\subsection{Geochemical analyses}

Concentration of dissolved thiosulfate in the pore-waters of the sediment-samples was determined by anion chromatography using an Eco IC (Metrohm AG, Herisau, Switzerland) 90 equipped with a conductivity detector (Metrohm, IC detector 1.850.9010). Chemical suppression was used for this purpose, while separation was carried using a Metrosep A Supp5 - 250/4.0 (6.1006.530) anion exchange column (Metrohm AG); a mixed solution of $1.0 \mathrm{mM}$ sodium hydrogen carbonate and $3.2 \mathrm{mM}$ sodium carbonate was used as the eluent; $100 \mathrm{mM}$ sulfuric acid was used as the regenerant; flow rate was $0.7 \mathrm{~mL} \mathrm{~min}^{-1}$, and injection volume $100 \mu \mathrm{L}$. Prior to 95 analysis, pore-water samples were diluted 1000-fold with de-ionized water (Siemens, <0.06 $\mu S$ ) and passed through $0.22 \mu \mathrm{m}$ hydrophilic polyvinylidene fluoride membranes (Merck Life Science Private Limited, Bengaluru, India). Sigma-Aldrich (St. Louis, MO, USA) standard chemicals were used to prepare the calibration curve for quantification. Overall sample reproducibility was \pm 0.2 ppm.

Presence of iron and manganese in the bulk sediment-samples was determined by X-ray fluorescence (XRF) spectrometry using an ARTAX 200 portable $\mu$-XRF spectrometer (Bruker Scientific Instruments, Billerica, MA, USA) having an Mo Tube X-ray source and Si-drift detector. Voltage and current used to excite the secondary fluorescence X-rays were $50 \mathrm{kV}$ and $698 \mu \mathrm{A}$, respectively; other operational parameters were as follows: count rate, $1877 \mathrm{cps}$; optic used to collect the emitted secondary X-rays, Collimator 0.650; live time, $60 \mathrm{~s}$; dead time, $0.4 \%$; atmosphere in which samples were analyzed, air. Subsequently, the two elements were quantified in the bulk sediment-samples using an Agilent 240 AA flame-atomic absorption spectrometer (FAAS) (Agilent Technologies, Santa Clara, CA, USA). Sediment-samples were prepared following the United States Environmental Protection Agency's prescribed method for acid digestion of sediments, sludge and soils (protocol number 3050B), where $0.5 \mathrm{~g}$ sedimentsample was taken in a beaker containing $50 \mathrm{~mL}$ distilled water plus $10 \mathrm{~mL}$ each of concentrated nitric acid and hydrochloric acid; the beaker was covered with watch glass and placed on a hot plate; digestion was continued until silica alone remained as the precipitate; finally the sample was cooled and filtered; volume was adjusted to $100 \mathrm{~mL}$ with distilled water, and then that 115 solution was analyzed by FAAS. The FAAS instrument was operated with the wavelengths 248.3 and $279.5 \mathrm{~nm}$ for iron and manganese respectively; lamp current for both elements was $5 \mathrm{~mA}$; fuel gas used was acetylene, while support gas was air; oxidizing condition was used for flame stoichiometry. For preparing standard curves ICP multi-element standard solution IV (Merck 
$\mathrm{KGaA}$, Darmstadt, Germany) was used at a concentration of $1000 \mathrm{mg} \mathrm{mL}^{-1}$.To estimate pyrite,

acid volatile sulfur (AVS) and chromium reducible sulfur (CRS) were extracted sequentially with cold $6 \mathrm{~N} \mathrm{HCl}$ and boiling $1 \mathrm{M} \mathrm{CrCl}_{2}$ in $6 \mathrm{~N} \mathrm{HCl}$ solution in an oxygen-free environment, as described previously (Mazumdar et al., 2012). The evolved $\mathrm{H}_{2} \mathrm{~S}$ was precipitated as $\mathrm{Ag}_{2} \mathrm{~S}$ for quantification of CRS and AVS. Whereas AVS was not detected in the samples from SSK42/5 and 6, the CRS values represented the $S$ contributed from the $\mathrm{FeS}_{2}$ (pyrite) present.

\subsection{Extraction of total DNA/RNA from sediment-samples/pure-culture isolates}

Total community DNA was extracted from the sediment-samples using PowerSoil DNA Isolation Kit (MoBio, Carlsbad, CA, USA), as per the manufacturer's protocol. Microgram-level of DNA was obtained from each batch of preparatory reaction that started with $0.5 \mathrm{~g}$ sediment-sample. 130 Genomic DNA of pure culture isolates was extracted using HiPurA Bacterial Genomic DNA Purification Kit (Himedia Laboratories, Mumbai, India), following manufacturer's instructions. Total community RNA was extracted from the $275 \mathrm{cmbsf}$ sediment-sample of SSK42/6 using the RNA PowerSoil Total RNA Isolation Kit (MoBio), as per manufacturer's protocol. Nanogram-level total RNA was obtained after pooling up the products of 15 individual preparatory reactions, each 135 carried out using $2 \mathrm{~g}$ sediment-sample. All the individual RNA preparations were subjected to DNase digestion by RNase free DNase I (Thermo Fisher Scientific, Waltham, MA, USA) and purified using RNeasy MinElute Cleanup Kit (Qiagen, Hilden, Germany); their concentrations were measured using Quant-iT RiboGreen RNA Assay Kit (Thermo Fisher Scientific). Integrity of RNA (RIN) within the individual preparations was determined on a TapeStation RNA ScreenTape

electrophoretic system (Agilent Technologies) and only high-quality preparations having RIN value $>7.0$ were added to the RNA pool that were subsequently used for sequencing library construction.

\subsection{Sequencing of metagenomes/metatranscriptome}

145 The duplicate set of total community DNA (metagenomes) isolated for each sediment-depth explored along SSK42/5 and 6 were shotgun sequenced individually on an lon Proton sequencing platform (Thermo Fisher Scientific) using 200 nucleotide read-chemistry, as described previously (Ghosh et al., 2015) (detailed procedure of metagenome sequencing is given in Supplementary Methods; complete lists of sedimentary communities investigated along

SSK42/5 and 6 are given in Tables S1 and S2 respectively).

The pooled up RNA species were selectively converted into a library of template molecules using TruSeq Stranded mRNA and Total RNA kit (Illumina Inc., San Diego, CA, USA). Depletion of rRNAs was carried out using the Ribo-Zero Gold system (Illumina Inc.), which is an integral part of the kit used for preparing the library. The rRNA-depleted RNA pool, which was 
expected to contain only the total mRNA, was fragmented into small pieces using divalent cations under elevated temperature. The cleaved RNA fragments were copied into first strand cDNAs using reverse transcriptase and random primers. This was followed by second strand CDNA synthesis using DNA Polymerase I and RNase H. cDNA fragments were then subjected to endrepair, addition of single ' $A$ ' bases, adaptor ligation, purification and enrichment with PCR to create the final library, which was sequenced on a HiSeq4000 platform (Illumina Inc.) using paired end, $2 \times 150$ nucleotide, sequencing by synthesis read-chemistry with dual indexing workflows. Furthermore, in order to extract and eliminate any rRNA read that may have been there in the raw metatranscriptomic sequence dataset, the 26,579,343 read-pairs available in all were mapped onto SILVA large subunit as well as small subunit rRNA gene sequence database 165 (Quast et al., 2013), using the short read aligner Bowtie2 v.2.3.4.3 (Langmead and Salzberg, 2012 ) in default local (sensitive) alignment mode. This identified $\sim 0.3 \%$ reads as ascribable to rRNAs, thereby leaving 26,496,769 read-pairs in the final dataset used for downstream analyses.

\subsection{De novo assembly and annotation of metagenomes/metatranscriptome}

All metagenomic sequence datasets were quality-filtered with Phred score cut-off 20 using Fastx_toolkit 0.0.13.2 (http://hannonlab.cshl.edu/fastx_toolkit/download.html). High quality reads from the duplicate metagenomic sequence datasets available for each sediment-community were co-assembled using Megahit v1.2.x (Li et al., 2015) with the kmers 21, 29, 39, 59, 79, 99, 119 and 141 for a minimum contig-length of $100 \mathrm{bp}$; each assembly obtained in this way was qualitychecked using MetaQUAST (Mikheenko et al., 2016), and >100-bp-long contigs were searched for ORFs/genes encoding >30-amino-acids-long peptides using MetaGeneMark (Zhu et al., 2010).

The rRNA-sequence-free metatranscriptomic dataset was assembled using the python script rnaspades.py, available within SPAdes 3.13.0 (Nurk et al., 2013), with default parameters.

180 ORFs/genes encoding continuous stretches of minimum 30 amino acids were predicted in contigs longer than 100 bp using Prodigal v2.6.3 (Hyatt et al., 2010).

Gene-catalogs obtained from the individual metagenomes/metatranscriptome were functionally annotated by searching against EggNOG v5.0 database (http://eggnog5.embl.de/download/eggnog_5.0/) with EggNOG-mapper (Huerta-Cepas et al., 185 2016) (http://beta-eggnogdb.embl.de/\#/app/emapper) using HMMER algorithms. Enzymes involved in tetrathionate formation, tetrathionate oxidation, tetrathionate respiration, and manganese oxidation were screened manually on the basis of their KEGG Orthology numbers (Kanehisa et al., 2016). 


\subsection{Direct taxonomic/functional annotation of raw metagenomic/metatranscriptomic reads}

Raw (unassembled) reads contained in the duplicate metagenomic sequence datasets obtained for each sediment-community were directly annotated taxonomically by separately searching against the non-redundant $(n r)$ protein sequence database of National Center for Biotechnology 195 Information (NCBI), Bethesda, MD, USA, using the Organism Abundance tool of MG-RAST 3.6 (Meyer et al., 2008). The two independent values obtained in this way for the relative abundances of taxa within a community (namely, genera of tetrathionate-formers, oxidizers and reducers, and genera of manganese-depositors and oxidizers) were averaged and used for comparisons between communities. In these analyses, percentage allocation of reads over various taxa was taken as a direct measure of the prevalence of those taxa within the community (Ghosh et al., 2015). Within MG-RAST, sequences were trimmed to contain no more than 5 successive bases with phred score $<15$. To classify reads using Organism Abundance tool, Best Hit Classification algorithm was followed [BlastX search with minimum 45 nucleotides (15 amino acids) alignment and $\geq 60 \%$ identity, and maximum e-value allowed $1 e^{-5}$.

\subsection{Slurry culture experiments}

Abilities of the individual sediment-samples to oxidize thiosulfate, and oxidize/reduce tetrathionate, were tested via aerobic slurry incubation experiments conducted at $15^{\circ} \mathrm{C}$ on a rotary shaker (150 rpm). For each experiment, $0.5 \mathrm{gm}$ sediment was suspended in $5 \mathrm{~mL}$ ASWT or ASWTr broth medium and incubated for 30 days. ASWT or ASWTr medium (pH 7.5) contained artificial sea water (ASW) supplemented with $\mathrm{Na}_{2} \mathrm{~S}_{2} \mathrm{O}_{3} .5 \mathrm{H}_{2} \mathrm{O}(10 \mathrm{mM})$ or $\mathrm{K}_{2} \mathrm{~S}_{4} \mathrm{O}_{6}(5 \mathrm{mM})$, added separately after filter-sterilization (Alam et al., 2013). ASW contained the following $\mathrm{L}^{-1}$ distilled

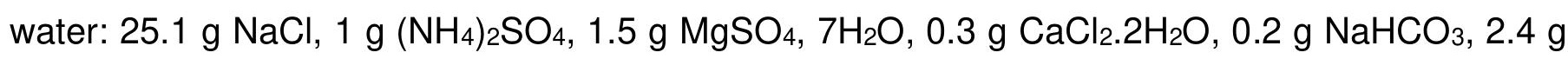
Tris, $1 \mathrm{~mL}$ trace element solution and $0.5 \mathrm{~g} \mathrm{~K}_{2} \mathrm{HPO}_{4}$ (added after autoclaving separately). $1 \mathrm{~L}$ 215 trace element solution ( $\mathrm{pH}$ 6.0), in turn, contained $50 \mathrm{~g} \mathrm{EDTA,} 22 \mathrm{~g} \mathrm{ZnSO}_{4} .7 \mathrm{H}_{2} \mathrm{O}, 5.06 \mathrm{~g} \mathrm{MnCl}_{2}$,

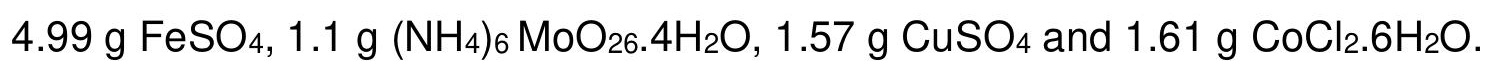

To check the tetrathionate-reducing ability of a sample, $2.5 \mathrm{gm}$ sediment was suspended in $45 \mathrm{~mL}$ Rappaport Vassiliadis tetrathionate medium (Vassiliadis, 1983) that was contained, and already autoclaved, in a screw-capped bottle. Sediment addition to the medium and subsequent incubation (for 30 days) of the screw-capped bottles were all carried out inside a Whitley H35 Hypoxystation (Don Whitley Scientific, West Yorkshire, UK) preset at $75 \%$ humidity, $15^{\circ} \mathrm{C}$ temperature and $0 \%$ partial pressure of $\mathrm{O}_{2}$, using the gas mixture $\mathrm{N}_{2}: \mathrm{H}_{2}: \mathrm{CO}_{2}=80: 10: 10(\mathrm{v} / \mathrm{v} / \mathrm{v})$. RVTr medium ( $\mathrm{pH} 5.4$ ) contained the following $\mathrm{L}^{-1}$ of distilled water: $4.5 \mathrm{~g}$ soya peptone, $8.0 \mathrm{~g}$ $\mathrm{NaCl}, 0.4 \mathrm{~g} \mathrm{~K}_{2} \mathrm{HPO}_{4}, 0.6 \mathrm{~g} \mathrm{KH}_{2} \mathrm{PO}_{4}, 29.0 \mathrm{~g} \mathrm{MnCl}_{2}, 0.036 \mathrm{~g}$ Malachite green, $10 \mathrm{mM} \mathrm{K} \mathrm{S}_{4} \mathrm{O}_{6}$

225 (added separately after filter sterilization) and $0.5 \mathrm{~g}$ sodium thioglycolate (to eliminate $\mathrm{O}_{2}$ ) and 0.1 $\mathrm{mg}$ resazurin (to indicate presence of any $\mathrm{O}_{2}$ ). 
Concentration of thiosulfate, tetrathionate and sulfate in the media were measured by iodometric tritation, cyanolysis and gravimetric sulfate precipitation method respectively at different time intervals (Alam et al., 2013). Dissolved sulfides were precipitated from the spent 230 media and subjected to colorimetric measurement based on the principle that N, N-dimethyl-pphenylenediaminedihydrochloride and $\mathrm{H}_{2} \mathrm{~S}$ react stoichiometrically in the presence of $\mathrm{FeCl}_{3}$ and $\mathrm{HCl}$ to form a blue-colored complex (Cline, 1969).

\subsection{Enrichment, isolation and characterization of bacterial strains}

235 Isolation of sulfur chemolithotrophs from the $275 \mathrm{cmbsf}$ sediment-sample of SSK42/6 was carried out in mineral salt-thiosulfate-yeast extract (MSTY) and ASWT/ASWTY media. While the ASWTY medium was a yeast extract $\left(500 \mathrm{mg} \mathrm{L}^{-1}\right)$ supplemented derivative of ASWT, MSTY contained modified basal and mineral salts (MS) solution supplemented with $20 \mathrm{mM} \mathrm{Na} 2 \mathrm{~S}_{2} \mathrm{O}_{3} .5 \mathrm{H}_{2} \mathrm{O}$ and $500 \mathrm{mg} \mathrm{L}^{-1}$ yeast extract ( $\mathrm{pH}$ 7.0). MS, in turn, contained the following $\mathrm{L}^{-1}$ distilled water: $1 \mathrm{~g}$

$240 \mathrm{NH}_{4} \mathrm{Cl}, 4 \mathrm{~g} \mathrm{~K}_{2} \mathrm{HPO}_{4}, 1.5 \mathrm{~g} \mathrm{KH}_{2} \mathrm{PO}_{4}, 0.5 \mathrm{~g} \mathrm{MgSO}_{4} .7 \mathrm{H}_{2} \mathrm{O}$ and $5.0 \mathrm{~mL}$ trace metals solution (Vishniac and Santer, 1957). Three portions of the 275-cmbsf sediment-sample of SSK42/6 were added $(5 \% \mathrm{w} / \mathrm{v})$ individually to MSTY, ASWT and ASWTY and broths, and incubated aerobically at $15^{\circ} \mathrm{C}$ until phenol red indicator present in the media turned yellow (apparently due to production of sulfuric acid from thiosulfate). Post yellowing, individual enrichment slurries were 245 kept undisturbed for $1 \mathrm{~h}$ to allow sediment particles to settle down; $10 \mathrm{~mL}$ cell suspension from each flask was then centrifuged at $6000 \mathrm{~g}$ for $10 \mathrm{~min}$ and the pellet re-suspended in $1 \mathrm{~mL}$ of the corresponding medium, serially diluted, and spread onto agar plates of the corresponding medium, and incubated at $15^{\circ} \mathrm{C}$. Morphologically distinct colonies were picked up and dilution streaked till all colonies in individual plates looked similar; representative colonies from individual 250 pure-plates were taken as strains and maintained in their respective isolation-media. Only Methylophaga, though isolated in ASWT, was maintained in ASW supplemented with $0.3 \%(\mathrm{v} / \mathrm{v})$ methanol (i.e. ASWM) because its growth in ASWT waned after six straight sub-cultures.

Chemolithotrophic capabilities of the new isolates were tested in MSTY, MSTrY, ASWT, ASWTY, ASWTM, ASWTr. MSTrY contained MS solution supplemented with $10 \mathrm{mM} \mathrm{K}_{2} \mathrm{~S}_{4} \mathrm{O}_{6}$ and $500 \mathrm{mg} \mathrm{L}^{-1}$ yeast extract; ASWTM contained ASW supplemented with $10 \mathrm{mM} \mathrm{Na} 2 \mathrm{~S}_{2} \mathrm{O}_{3} .5 \mathrm{H}_{2} \mathrm{O}$ and $0.3 \%(\mathrm{v} / \mathrm{v})$ methanol; ASWTr contained ASW supplemented with $10 \mathrm{mM} \mathrm{K}_{2} \mathrm{~S}_{4} \mathrm{O}_{6}$. Concentrations of dissolved thiosulfate, tetrathionate and sulfate in the spent media were measured as already described above.

Tetrathionate-reducing bacterial strains were isolated from the $275 \mathrm{cmbsf}$ sediment260 sample of SSK42/6 in RVTr medium (Vassiliadis, 1983) under strictly anaerobic condition. $2.5 \mathrm{~g}$ sediment-sample was added to $45 \mathrm{~mL}$ RVTr broth that was contained, and already autoclaved, in a screw-capped bottle. Sediment addition to the medium, and subsequent incubation of the 
screw-capped bottles at $15^{\circ} \mathrm{C}$ for one month, were all carried out inside the Whitley H35 Hypoxystation preset to zero $\mathrm{O}_{2}$ as stated above. After one month, still inside the Hypoxystation, $2651 \mathrm{~mL}$ of the sediment- RVTr slurry was serially diluted and spread onto RVTr agar plates and incubated at $15^{\circ} \mathrm{C}$. After growth appeared in the RVTr agar plates, they were taken out, repeatedly dilution streaked on to fresh plates and incubated aerobically, till all colonies in the individual plates looked similar. Representative colonies from the pure-plates were taken as strains and maintained in aerobically in Luria Bertani medium. The pure isolates obtained in this way were classified down to the lowest identifiable taxonomic category, as described above for the sulfur-oxidizing isolates. Tetrathionate-reducing abilities of the new isolates were tested by growing them for 30 days in RVTr broth, inside the H35 Hypoxystation, as described above. Concentrations of dissolved thiosulfate, tetrathionate and sulfide in the spent RVTr medium were also measured as before.

Genomic DNA was extracted from the isolated strains using HiPurA Bacterial Genomic DNA Purification Kit (Himedia Laboratories) following manufacturer's protocol. Using their genomic DNA as template, 16S rRNA genes were PCR amplified from the individual bacterial isolates strains using the Bacteria-specific universal primer-pair $27 f$ and 1492r (Gerhardt, 1994). 16S rRNA gene sequences were determined from the PCR products using the same universal 280 primers; according to the manufacturer's instructions for a 3500xL Genetic Analyzer automated DNA sequencer (Thermo Fisher Scientific). The 16S rRNA gene sequence of each strain was compared against sequences available in the GenBank/EMBL/DDBJ databases, using BLASTN; strains were finally classified down to the lowest identifiable taxonomic category on the basis of their 16S rRNA gene sequence similarities with the closest, validly-published species having standing in nomenclature (http://www.bacterio.net/; see also Euzéby, 1997; Parte, 2013).

\section{Results and discussion}

\subsection{Study site and samples}

During the comprehensive exploration of the sediment biogeochemistry of eastern Arabian Sea 290 OMZ (ASOMZ) on-board RV Sindhu Sankalp (SSK42), the two gravity cores SSK42/5 and SSK42/6, on which the present study is based, were collected from $580 \mathrm{mbsl}\left(16^{\circ} 49.88^{\prime} \mathrm{N}\right.$, $71^{\circ} 58.55^{\prime} \mathrm{E}$ ) and $530 \mathrm{mbsl}\left(16^{\circ} 50.03^{\prime} \mathrm{N}, 71^{\circ} 59.50^{\prime} \mathrm{E}\right.$ ) water-depths respectively (Fernandes et al., 2018). These two sediment-cores, collected from the approximate center of the vertical expanse of the ASOMZ off the west coast of India, were both $295 \mathrm{~cm}$ long. Onboard-sampling of 295 the cores was carried out at 15 to $30 \mathrm{~cm}$ intervals; adequate measures were taken to avoid postsampling contamination of the native microbial communities and physicochemical alteration of the native geochemical properties of the sediments (Fernandes et al., 2018). Sediment-samples were subjected to culture-independent and culture-dependent investigations to reveal the 
structures and functions of the in situ microbial communities; pore-water/solid-phase chemistry was characterized using a range of analytical techniques; the geomicrobiology was then considered in the context of the in situ sulfur cycle and potential tetrathionate metabolism.

\subsection{Tetrathionate-forming, oxidizing, or respiring genes and relevant microorganisms are} abundant in the sediment horizon of SSK42/5 and 6

305 When the metagenomic sequence data obtained for each of the 25 distinct sediment-samples of SSK $42 / 5$ and 6 were assembled and annotated individually, 23 out of the 25 contig-collections obtained were found to contain genes for tetrathionate formation (namely, genes encoding subunits of the thiosulfate dehydrogenases TsdA and DoxDA) (Table S3), while all the 25 contigcollections contained genes for tetrathionate oxidation (namely, thiol esterase soxB and sulfur 310 dehydrogenase soxC (Table S4). Furthermore, 23 out of the 25 contig-collections were found to contain genes for tetrathionate reduction (namely genes encoding subunits of tetrathionate reductase TtrABC and thiosulfate reductases PhsAB and PsrA) (Table S5). tsdA (Denkmann et al., 2012; Pyne et al., 2018) and $\operatorname{doxDA}$ (Quatrini et al., 2009) are known to be involved in thiosulfate to tetrathionate conversion by taxonomically diverse chemolitho/heterotrophic 315 bacteria. soxB and $\operatorname{sox} C$ are known to be involved in tetrathionate (as well as thiosulfate) oxidation by taxonomically diverse chemolithotrophic bacteria (Friedrich et al., 2001, 2005; Lahiri et al., 2006; Alam et al., 2013; Pyne et al., 2018; Mandal et al., unpublished data). In diverse tetrathionate-respiring species, $\operatorname{tr} A B C$ reduce tetrathionate to thiosulfate or sulfide (Barrett and Clark, 1987), while phsAB and psrA convert thiosulfate to sulfide (Stoffels et al., 2011).

Concurrent with the above findings, direct taxonomic annotation of the raw (unassembled) metagenomic sequence data (by searching against the $n r$ protein sequence database of NCBI) revealed that considerable proportions of the reads obtained from the individual sediment-depths of SSK42/5 and 6 were ascribable to bacterial genera whose members are known to render tetrathionate formation, oxidation or respiration. In that way, $1.3-4.36 \%$ and $3-7.8 \%$ of metagenomic reads obtained from the individual sample-sites of SSK42/5 (Fig. 1) and 6 (Fig. 2) were ascribable to the genera Pseudomonas and Halomonas, marine strains of which are known to form tetrathionate from the oxidation of thiosulfate (Tuttle, 1980; Sorokin, 2003). Likewise, 0.1 1.5 and $0.4-6.4 \%$ of metagenomic reads obtained from the individual sample-sites of SSK42/5 (Fig. 1) and 6 (Fig. 2) were ascribable to the genera Acidithiobacillus, Halothiobacillus and 330 Thiomicrospira, all members of which oxidize tetrathionate chemolithotrophically (Ghosh and Dam 2009); on the other hand, $0.1-0.3$ and $0.2-0.4 \%$ of metagenomic reads obtained from the individual sample-sites of SSK42/5 (Fig. 1) and 6 (Fig. 2) were ascribable to the genera Citrobacter, Proteus and Salmonella, all members of which respire by reducing tetrathionate to thiosulfate and/or sulfide (Kaprálek, 1972; Barrett and Clark, 1987; Price-Carter et al., 2001). 
3.3 Synchronized population-fluctuation of different tetrathionate-metabolizing types, along SSK42/5 and 6

Analyses based on the direct taxonomic annotation of the unassembled metagenomic data from discrete sediment-depths of SSK42/5 revealed that the relative abundances of reads ascribed to the genera of tetrathionate-forming, oxidizing, and respiring bacteria fluctuate synchronously 340 along this sediment core (Fig. 1). Corroboratively, pair-wise Pearson correlation coefficients (CC) as well as Spearman rank correlation coefficients (RCC) between the prevalence of the three metabolic-types are also significantly high in SSK42/5 (Fig. 1; Table S6), which indicate the existence of strong syntrophic interdependence between the three tetrathionate-metabolizing types in this sediment horizon. Fluctuations in the prevalence of the three metabolic-types,

345 however, are less synchronous along SSK42/6 (Fig. 2) and corresponding correlation values are also relatively weaker (Table S7).

Consistent prevalence of reads ascribed to the thiosulfate-to-tetrathionate-converting bacterial genera Halomonas and Pseudomonas in the metagenomes isolated from the different sample-sites of SSK42/5 and 6 (Fig. 1 and 2) indicated that tetrathionate could be bioavailable in

the chemical milieu of this sediment horizon (notably, pure-culture strains belonging to these two genera were also isolated from the $275 \mathrm{cmbsf}$ sample of SSK42/6; see section 5.3 below, and also Fig. 3). Apart from these two, several such genera were also found to be well represented in the metagenomes of SSK42/5 and 6, some or all members of which are known to produce tetrathionate as a free intermediate during the oxidation thiosulfate to sulfate (Tables S8 and S9). These organisms, namely Acidithiobacillus, Advenella, Halothiobacillus, Pusillimonas and Thiomicrospira, can well increase tetrathionate availability in the ASOMZ sediments, even as they themselves are potential users of the tetrathionate (Kelly and Wood, 2000; Sievert et al., 2000; Boden et al., 2017). Tetrathionate can also be formed in situ, as an intermediate of sulfate/sulfite reduction, by members of the genera Desulfovibrio and Desulfobulbus (Sass et al., 360 1992), which were detected along both the cores via direct taxonomic annotation of the unassembled metagenomic data (see Tables S8 and S9 for the percentages of metagenomic reads ascribed to these genera in the different sediment-samples).

Tetrathionate can be oxidized in situ as a potential energy and electron source by obligately chemolithotrophic genera such as Acidithiobacillus, Halothiobacillus and 365 Thiomicrospira (Ghosh and Dam 2009) that were detected via direct taxonomic annotation of the unassembled metagenomic data (Fig. 1 and 2) and/or isolated as pure cultures from the 275 cmbsf sample of SSK42/6 (Fig. 3). Whilst all members of these genera are known to oxidize tetrathionate to sulfate (Kelly and Wood, 2000; Sievert et al., 2000; Boden et al., 2017), several such genera were also detected (via direct annotation of metagenomic reads) along SSK42/5 and 6 , some chemolithotrophic members of which are known to oxidize tetrathionate to sulfate. 
These organisms, such as Advenella, Bosea, Burkholderia, Campylobacter, Hydrogenovibrio, Pandoraea, Pusillimonas, Pseudaminobacter, Sulfurivirga, Thiohalorhabdus, and Thiobacillus (see Tables S10 and S11 for the metagenomic read percentages ascribed to these genera in the different sediment-samples) may contribute to further tetrathionate depletion from the sediments.

Tetrathionate in the ASOMZ sediments can also be utilized as a respiratory substrate by tetrathionate-reducing bacteria such as Citrobacter, Proteus and Salmonella, which were detected by direct annotation of metagenomic reads (Fig. 1 and 2) and all members of which are known to respire tetrathionate (Kaprálek, 1972; Barrett and Clark, 1987; Price-Carter et al., 2001). In addition, strains of Enterobacter such as those isolated as pure cultures from 275 380 cmbsf of SSK42/6 (Fig. 3) can add to the depletion of tetrathionate from the sediments. Furthermore, several such genera were also detected along SSK42/5 and 6 (via direct annotation of metagenomic reads), some members of which are known to respire tetrathionate in the absence of $\mathrm{O}_{2}$ - these included Alteromonas, Alcaligenes, Desulfotomaculum, Desulfovibrio, Edwardsiella, Morganella, Pasteurella, Providencia, Serratia and Shewanella (see Tables S12 and $\mathrm{S} 13$ for the metagenomic read percentages ascribed to these genera in the different sediment-samples).

\subsection{The tetrathionate-forming/oxidizing microorganisms of the ASOMZ sediments are alive and active in situ}

390 Most of the sulfur chemolithotrophic bacteria known thus far, including those which form tetrathionate from thiosulfate and/or oxidize tetrathionate to sulfate, use molecular oxygen $\left(\mathrm{O}_{2}\right)$ as the terminal electron acceptor (Ghosh and Dam 2009). So it is apparently peculiar that such microorganisms could be alive and active in the sulfide-rich sediments of SSK42/5 and 6 (Fernandes et al., 2018; also see Table 1) located at the center of the ASOMZ, where $\mathrm{O}_{2}$ 395 penetration depth of the sediments is generally very low (Breuer et al., 2009). However, in a recent study of sedimentary microbial ecology of SSK42/5 and 6 we have revealed that cryptic $\mathrm{O}_{2}$-sources such as perchlorate respiration enable taxonomically and metabolically diversified communities of aerobic bacteria thrive in this outwardly-anoxic environment (Bhattacharya et al., Under Revision in Nature Communications). Consistent to the findings of that paper, present 400 aerobic slurry incubations of most of the sediment-samples of SSK42/5 and 6 in thiosulfatecontaining artificial sea water (ASWT) medium resulted in the formation of tetrathionate and/or sulfate, thereby illustrating the live status of the tetrathionate-forming/oxidizing microflora. In SSK42/5, tetrathionate was the sole end-product of thiosulfate oxidation in slurry incubations of the $0,15,90$ and $160 \mathrm{cmbsf}$ sediment-samples. These samples converted thiosulfate only up to 405 tetrathionate at a rate of $6.45-17.72 \mu \mathrm{mol} \mathrm{S}$ day $^{-1} \mathrm{~g}_{\text {sediment }}{ }^{-1}$ respectively (Table S14). In contrast, the 45, 60 and $295 \mathrm{cmbsf}$ samples of SSK42/5 first converted thiosulfate to free and 
detectable tetrathionate at a rate of 1.11-6.45 $\mu \mathrm{mol} \mathrm{S}$ day $^{-1} \mathrm{~g}_{\text {sediment }}{ }^{-1}$; whilst no sulfate was produced during this period of incubation, the accumulated tetrathionate was subsequently converted to sulfate at a rate of 5.86-13.75 $\mu \mathrm{mol} \mathrm{S} \mathrm{day}^{-1} \mathrm{~g} \mathrm{sediment}^{-1}$ (Table S15). Samples from 410 the rest of the five sediment-depths explored in SSK42/5 did not metabolize thiosulfate at all. In SSK42/6, tetrathionate was the sole end-product of thiosulfate oxidation in slurry incubations of the 120,175 and $275 \mathrm{cmbsf}$ sediment-samples. These samples converted thiosulfate only up to tetrathionate at a rate of 17.2-29.71 $\mu \mathrm{mol} \mathrm{S} \mathrm{day}{ }^{-1} \mathrm{~g}_{\text {sediment }}{ }^{-1}$ (Table S16). In contrast, the 2, 30 and $45 \mathrm{cmbsf}$ samples of SSK42/6 first converted thiosulfate to free and detectable tetrathionate 415 at a rate of 21.05-33.68 $\mu \mathrm{mol} \mathrm{S}$ day $^{-1} \mathrm{~g}_{\text {sediment }}{ }^{-1}$; whereas no sulfate was produced during this period of incubation, the accumulated tetrathionate was subsequently converted to sulfate at a rate of 24-54 $\mu \mathrm{mol} \mathrm{S}$ day $^{-1} \mathrm{~g}_{\text {sediment }}{ }^{-1}$ (Table S17). Samples from the rest of the seven sediment-depths explored in SSK42/6 did not metabolize thiosulfate at all.

During aerobic slurry incubations in tetrathionate-containing artificial sea water (ASWTr) 420 chemolithotrophic medium, a number of sediment-samples oxidized tetrathionate to sulfate. Of the SSK42/5 samples, those from 0, 15, 45, 90, 120, 160 and $295 \mathrm{cmbsf}$ sediment-depths oxidized tetrathionate at a rate of 2.5-23.5 $\mathrm{mol} \mathrm{S} \mathrm{day}^{-1} \mathrm{~g} \mathrm{sediment}^{-1}$ (Table S18). Samples from the remaining five sediment-depths explored in SSK42/5 did not oxidize tetrathionate. In SSK42/6, sediment-samples from 2, 30, 45, 60, 75 and $90 \mathrm{cmbsf}$ oxidized tetrathionate at a 425 similar rate of $141( \pm 1) \mu \mathrm{mol} \mathrm{S}$ day $^{-1} \mathrm{~g}^{-1}$ sediment, while the samples from 120, 135 and 175 cmbsf did so at a common rate of $40( \pm 1) \mu \mathrm{mol} \mathrm{S}$ day $^{-1} \mathrm{~g} \mathrm{sediment}^{-1}$, and those from 220, 250, 265 and 275 cmbsf at $75( \pm 2) \mu \mathrm{mol} \mathrm{S}$ day $^{-1} \mathrm{~g}_{\text {sediment }}{ }^{-1}$.

Results of the slurry culture experiments illustrated that tetrathionate-forming and oxidizing bacteria of SSK42/5 and 6 were alive in situ. In order to further verify whether these metabolic430 types were functionally (metabolically) active in their native habitat, whole metatranscriptome of the 275 cmbsf sediment-sample of SSK42/6 was sequenced, and the paired end reads assembled into contigs. The gene-catalog obtained via annotation of the assembled contigs were found to encompass homologs of thiosulfate dehydrogenase (tsdA), thiol esterase (soxB) and sulfur dehydrogenase (soxC) (Table S19).

Furthermore, from $275 \mathrm{cmbsf}$ of SSK42/6, 15 such aerobic bacterial strains were isolated in different chemolithoautotophic/mixotrophic thiosulfate-containing media (Table 2) that could form tetrathionate from thiosulfate and/or oxidize tetrathionate to sulfate when grown in corresponding chemolithoautotophic/mixotrophic medium (Fig. 3). 16S rRNA gene sequencebased taxonomic identification of the isolates clustered them under six species-level entities 440 belonging to six distinct genera - the isolates belonging to the genera Halomonas, Methylophaga, Pseudomonas and Stenotrophomonas formed tetrathionate from thiosulfate, while those belonging to Pusillimonas not only formed tetrathionate from thiosulfate but also 
oxidized tetrathionate to sulfate; the Halothiobacillus isolates did not form tetrathionate and only oxidized the same to sulfate (Table 2). Tetrathionate-forming and/or oxidizing phenotypes of one representative strain each from the six species-level clusters are shown in Fig. 3.

\subsection{Active tetrathionate-reducing microorganisms in ASOMZ sediment}

During anerobic slurry incubation in heterotrophic Rappaport Vassiliadis medium supplemented with tetrathionate as the sole electron acceptor (RVTr), all the sediment-samples from SSK42/5

and 6 reduced tetrathionate to thiosulfate and/or sulfide at a rate of $0.5-1.5 \mu \mathrm{mol} \mathrm{S}$ day $^{-1} \mathrm{~g}$ sediment $^{-1}$ (Tables S20 and S21). Notably, no tetrathionate reductase (ttrABC) or thiosulfate reductases ( $p h s A B$ or $p s r A$ ) were detected in the gene-catalog obtained via assembly and annotation of the metatranscriptomic data from $275 \mathrm{cmbsf}$ of SSK42/6; nevertheless, the same catalog did contain many genes having highest sequence identities with functionally diverse genes belonging to the typical tetrathionate-reducer Salmonella.

Furthermore, anaerobic enrichment of the $275 \mathrm{cmbsf}$ sediment-samples of SSK42/6, followed by isolation of pure cultures, in RVTr medium yielded four tetrathionate-respiring strains that reduced 30-32 mM S tetrathionate into equivalent amount of thiosulfate over $72 \mathrm{~h}$ incubation in RVTr medium (Fig. 3H shows the tetrathionate-reduction kinetics of one representative strain). 460 16S rRNA gene sequence-based taxonomic identification of the four isolates clustered them under a single species-level entity belonging to Enterobacter (Table 2).

\subsection{Thiosulfate and pyrite as key sources of tetrathionate in the OMZ sediments: linking iron and manganese with the sulfur cycle}

465 In marine sediments, abiotic oxidation of pyrite $\left(\mathrm{FeS}_{2}\right)$ by $\mathrm{MnO}_{2}$ can lead to the formation of tetrathionate as well as thiosulfate, trithionate, pentathionate and sulfate (Jørgensen and Bak, 1991; Luther, 1991; Berner and Petsch, 1998). The thiosulfate formed in this ways can again be oxidized to tetrathionate either microbially (as mentioned above) or via abiotic reaction with $\mathrm{MnO}_{2}$. Corroborative to these possibilities, results of geochemical analyses (Table 1) revealed up

to $11.1 \mu \mathrm{M}$ thiosulfate in the pore-waters of all the sulfide-containing sample-sites of SSK42/5 and 6 (tandem absence of sulfide and thiosulfate in the upper $15 \mathrm{cmbsf}$ of SSK42/6 could be due to potentially high rates of chemolithotrophic conversion of sulfide/thiosulfate to sulfate in situ). Presence of Fe (9232-17234 ppm), Mn (71-172 ppm) and pyrite (0.05-1.09 wt \%) in the solid phase of both the cores (Table 1) lend support to the feasibility of the inorganic sulfide oxidation 475 pathway envisaged above. Furthermore, when the metagenomic sequence data obtained for each of the 25 distinct sediment-samples of SSK42/5 and 6 were assembled and annotated individually, all 25 contig-collections obtained were found to contain genes for $\mathrm{Mn}$ (II) to $\mathrm{Mn}$ (IV) oxidation (Table S22). The gene-catalog obtained via assembly and annotation of the 
metatranscriptomic sequence data from $275 \mathrm{cmbsf}$ of SSK42/6 also encompassed homolog encoding manganese oxidase $(\cot A)$ and other accessory proteins involved in $\mathrm{Mn}(\mathrm{II})$ to $\mathrm{Mn}(\mathrm{IV})$ oxidation (Table S19). Reinforcing the above data, percentage of metagenomic reads ascribed (via direct taxonomic annotation of the raw/unassembled metagenomic reads) to bacteria such as Aeromonas, Citrobacter, Enterobacter Gallionella, Hyphomicrobium Leptothrix and Proteus that can deposit manganese oxide $\left(\mathrm{MnO}\right.$ ) in situ (by reducing $\mathrm{Mn}^{+4}$ to $\mathrm{Mn}^{+2}$ for anaerobic respiration; see Ghiorse, 1984) was found to be high throughout SSK42/5 and 6 (Fig. 1 and 2). By this type of analysis, again, bacteria which are known to produce $\mathrm{MnO}_{2}$ from $\mathrm{MnO}$ [these include Arthrobacter, Oceanospirillum and Vibrio (Tebo et al., 2005; Sujith and Bharathi, 2011)] were also found to be prevalent at all the sample sites (Fig. 1 and 2). In SSK42/5, significantly positive pair-wise correlation was also found to exist between the relative abundances of 490 metagenomic reads ascribed to the genera of MnO-depositing bacteria and tetrathionate-forming / tetrathionate-oxidizing / tetrathionate-reducing bacteria on one hand and $\mathrm{MnO}$-oxidizing bacteria and tetrathionate-forming / tetrathionate-oxidizing / tetrathionate-reducing bacteria on the other (Fig. 1). In SSK42/6, significant positive correlation was observed between MnO-depositing and tetrathionate-reducing bacteria (Fig 2). These data were reflective of a strong interdependence of $\mathrm{MnO}-$ depositing/MnO-oxidizing bacteria with the different tetrathionate-metabolizing groups.

\subsection{Concluding remarks}

Sulfur cycling is a crucial component of sediment biogeochemistry within the marine realm. Apart from controlling in situ sulfide-sulfate balance, microbe-mediated processes of the sulfur cycle work in conjunction with those of the carbon cycle to remineralize organic matters sequestered in the sea-bed, and also influence metal deposition/mobilization. Tetrathionate is seldom appreciated as a central intermediate of sulfur cycling in marine sediments, even though thiosulfate is long known to be a central biogeochemical junction of sedimentary sulfur cycling across the global ocean (Jørgensen, 1990; Jørgensen and Bak 1991; Thamdrup et al., 1994).

505 Thus far, only one study based on the Baltic Sea sediments has reported microbial production of tetrathionate and highlighted the role of tetrathionate in the sulfur cycle of Baltic Sea sediments (Podgorsek and Imhoff, 1999). The present geomicrobiological exploration of the sediments underlying the approximate-center of the $\sim 200-1200 \mathrm{mbsl}$ vertical-expanse of the Arabian Sea $O M Z$ revealed tetrathionate as a potent intermediate of the in situ sulfur cycle, and identified the 510 biotic and abiotic mechanisms that are plausibly involved in the formation and transformation of this polythionate. Albeit the cryptic biogeochemical roles of tetrathionate in the sulfur cycle were revealed here in the context of an oxygen minimum zone, it is noteworthy that there were no observable reasons to assume that such processes do not have their equivalents in other geomicrobiologically-distinct sediment horizons of the marine realm. 
Pyrites (via abiotic reaction with $\mathrm{MnO}_{2}$ ) and thiosulfate (via chemolithotrophic oxidation by members of the bacterial group designated as A in Fig. 4) are apparently the main sources of tetrathionate in the sulfidic sediment ecosystem explored. While pyrite can additionally contribute to the thiosulfate pool, sulfate-/sulfite-reduction (by members of the bacterial group designated as $A^{\prime}$ in Fig. 4) can act as an additional source of tetrathionate in situ. Tetrathionate formed in this way can have a number of fates: it can be converted to sulfate (via chemolithotrophic oxidation by members of the bacterial group designated as B in Fig. 4) or reduced back to thiosulfate (via respiration by members of the bacterial group designated as C in Fig. 4); copious hydrogen sulfide present in situ (Fernandes et al., 2018) can also reduce tetrathionate abiotically to thiosulfate and elemental sulfur (Rowe et al., 2015). Tetrathionate, remarkably, was not found to exist freely in the pore-waters of SSK42/5 and 6; this is apparently attributable to the fact that its build-up to measurable quantities is generally debarred in natural environments due to high reactivity of this polythionate under the mediation of microbes (Kanao et al., 2007; Ghosh and Dam, 2009; Boden et al., 2010; Pyne et al., 2017, 2018) as well as naturally-occurring chemical substances such as sulfide (Schippers et al., 1999; Schippers and Jørgensen, 2001). From that perspective, the in situ as well as in vitro geomicrobiological information unearthed in this study illustrates the power of meta-omics in discovering such invisible interfaces between the chemosphere and the biosphere that are almost impossible to decipher from preserved geochemical records alone.

\section{Supplementary material}

Supplemental material for this article may be found with the digital version of this manuscript.

\section{Data availability}

540 All nucleotide sequence data have been deposited in NCBI Sequence Read Archive (SRA) or GenBank under the BioProject accession number PRJNA309469: (i) the whole metagenome shotgun sequence datasets have the Run accession numbers SRR3646127 through SRR3646132, SRR3646144, SRR3646145, SRR3646147, SRR3646148, SRR3646150 through SRR3646153, SRR3646155 through SRR3646158, SRR3646160 through SRR3646165, and (ii) 545 the metatranscriptome sequence dataset has the Run accession number SRR7991972.

Code availability. All data analysis codes used in this study are in the published domain, and have been appropriately cited in the text. 


\section{Author contributions}

W.G. conceived the study, designed the experiments, interpreted the results and wrote the paper. A.M led the entire SSK42 mission and all geochemical investigations therein. S.M. anchored the whole microbiological work, performed the experiments, analyzed and curated the data. S.B., T.M., M.J.R. and C.R. performed microbiological experiments and data analysis. S.F. and A.P. performed geochemical experiments. All authors read and vetted the manuscript.

\section{Acknowledgements}

Financial support for conducting the microbiological studies was provided by given by Bose

Institute via internal faculty grants and Earth System Science Organization, Ministry of Earth Sciences (MoES), Government of India (Gol) via grant number MoES/36/00IS/Extra/19/2013. We thank the Director CSIR-National Institute of Oceanography for facilitating the geochemical studies and the research cruise SSK42 for acquisition of sediment cores. MoES (GAP2303) also funded the research cruise. All the support received from the CSIR-NIO Ship Cell members and

the crew members of SSK42 is gratefully acknowledged. S.B. received fellowship from Bose Institute. SM got fellowship from Department of Science and Technology, Gol. MJR and C.R. got fellowship from University Grants Commission, Gol. S.F. received fellowships from Council of Scientific and Industrial Research, Gol.

\section{References}

Alam, M., Pyne, P., Mazumdar, A., Peketi A and Ghosh, W: Kinetic enrichment of ${ }^{34} \mathrm{~S}$ during proteobacterial thiosulfate oxidation and the conserved role of SoxB in SS bond breaking, Appl Environ Microbiol, 79, 4455-4464, https://doi.org/10.1128/AEM.00956-13, 2013.

Barrett, EL and Clark, MA: Tetrathionate reduction and production of hydrogen sulfide from thiosulfate, Microbiol Rev, 51,192, 1987.

Berner, RA and Petsch, ST: The sulfur cycle and atmospheric oxygen, Sci, 282, 1426-1427, https://doi: 10.1126/science.282.5393.1426, 1998.

Baumgartner, LK., Reid RP., Dupraz, C., Decho, AW., Buckley, DH., Spear, JR., Przekop, KM and Visscher, PT: Sulfate reducing bacteria in microbial mats: changing paradigms, new discoveries, Sediment. Geol, 185,131-145, https://doi.org/10.1016/j.sedgeo.2005.12.008, 2006.

Breuer, ER., Law, GT., Woulds, C., Cowie, GL., Shimmield, GB., Peppe, O., Schwartz M and McKinlay, S: Sedimentary oxygen consumption and microdistribution at sites across the Arabian Sea oxygen minimum zone (Pakistan margin), Deep Sea Res. Part II Top. Stud. Oceanogr, 56, 296-304, https://doi.org/10.1016/j.dsr2.2008.06.010, 2009.

Boden, R., Kelly, D.P., Murrell, J.C. and Schäfer, H: Oxidation of dimethylsulfide to tetrathionate by Methylophaga thiooxidans sp. nov.: a new link in the sulfur cycle, Environ Microbiol, 12, 2688-2699, https://doi.org/10.1111/j.1462-2920.2010.02238.x, 2010.

Boden, R., Scott, KM., Williams, J., Russel, S., Antonen, K, Rae, AW and Hutt, LP: An evaluation of Thiomicrospira, Hydrogenovibrio and Thioalkalimicrobium: reclassification of four species of Thiomicrospira to each Thiomicrorhabdus gen. nov. and Hydrogenovibrio, and 
reclassification of all four species of Thioalkalimicrobium to Thiomicrospira, Int $\mathrm{J}$ Syst Evol Microbiol, 67, 1140-1151, https://doi: 10.1099/ijsem.0.001855, 2017.

Bhattacharya, S., Roy, C., Mandal, S., Rameez, MJ., Sarkar, J., Fernandes, S., Mapder, T., Alam, M., Roy, R., Mondal, N., Pyne, P., Haldar, P., Peketi, A., Chakraborty, R., Mazumdar A and Ghosh W: Crypto-aerobic microbial life in anoxic (sulfidic) marine sediments (Under review in Nature communications).

Cline, JD: Spectrophotometric determination of hydrogen sulfide in natural waters, Limnol Oceanogr, 14, 454-458, 1969.

600 Denkmann, K., Grein, F., Zigann, R., Siemen, A., Bergmann, J., van Helmont, S., Nicolai, A., Pereira, I.A. and Dahl, C: Thiosulfate dehydrogenase: a widespread unusual acidophilic c-type cytochrome, Environ Microbiol, 14, 2673-2688, https://doi.org/10.1111/j.14622920.2012.02820.x, 2012.

Euzéby, JP: List of Bacterial Names with Standing in Nomenclature: a folder available on the Internet, Int J Syst Evol Microbiol, 47, 590-592, https://doi:10.1099/00207713-47-2-590, 1997.

Friedrich, CG., Rother, D., Bardischewsky, F., Quentmeier, A and Fischer, J: Oxidation of reduced inorganic sulfur compounds by bacteria: emergence of a common mechanism?, Appl. Environ. Microbiol, 67,2873-2882, https:// doi:10.1128/AEM.67.7.2873-2882.2001, 2001.

Friedrich, CG., Bardischewsky, F., Rother, D., Quentmeier, A and Fischer, J. Prokaryotic sulfur oxidation, Curr Opin Microbiol, 8, 253-259, https://doi.org/10.1016/j.mib.2005.04.005, 2005.

Fernandes, S., Mazumdar, A., Bhattacharya, S., Peketi, A., Mapder, T., Roy, R., Carvalho, MA., Roy, C., Mahalakshmi, P., Silva, R., Rao, PS., Banik, S and Ghosh, W: Enhanced carbonsulfur cycling in the sediments of Arabian Sea oxygen minimum zone center, Sci Rep, 8:8665, https://doi.org/10.1038/s41598-018-27002-2, 2018.

Ghiorse, WC: Biology of iron-and manganese-depositing bacteria, Annu Rev Microbiol, 38, 515550, https://doi:10.1146/annurev.mi.38.100184.002503, 1984.

Ghosh, W., Bagchi, A., Mandal, S., Dam, B. and Roy, P: Tetrathiobacter kashmirensis gen. nov., sp. nov., a novel mesophilic, neutrophilic, tetrathionate-oxidizing, facultatively chemolithotrophic betaproteobacterium isolated from soil from a temperate orchard in Jammu and Kashmir, India, Int. J. Syst. Evol. Microbiol, 55, 1779-1787, https://doi:10.1099/ijs.0.63595-0, 2005.

Ghosh, W and Roy, P: Mesorhizobium thiogangeticum sp. nov., a novel sulfur-oxidizing chemolithoautotroph from rhizosphere soil of an Indian tropical leguminous plant, Int $J$ Syst Evol Microbiol, 56, 91-97, https://doi:10.1099/ijs.0.63967-0, 2006.

Ghosh, W. and Roy, P: Chemolithoautotrophic oxidation of thiosulfate, tetrathionate and thiocyanate by a novel rhizobacterium belonging to the genus Paracoccus. FEMS Microbiol Lett, 270, 124-131, https://doi.org/10.1111/j.1574-6968.2007.00670.x, 2007.

Ghosh, W. and Dam, B: Biochemistry and molecular biology of lithotrophic sulfur oxidation by taxonomically and ecologically diverse bacteria and archaea, FEMS Microbiol Rev, 33, 999-1043, https://doi.org/10.1111/j.1574-6976.2009.00187.x, 2009, 2009.

Ghosh, W., Roy, C., Roy, R., Nilawe, P., Mukherjee, A., Haldar, PK., Chauhan, NK., Bhattacharya, S., Agarwal, A., George, A and Pyne, P: Resilience and receptivity worked in tandem to sustain a geothermal mat community amidst erratic environmental conditions, Sci Rep, 5, 12179, https://doi:10.1038/srep12179, 2015. 
Hyatt, D., Chen, GL., LoCascio, PF., Land, M.L, Larimer, FW and Hauser, LJ: Prodigal: prokaryotic gene recognition and translation initiation site identification. BMC Bioinformatics, 11, 119, https://doi.org/10.1186/1471-2105-11-119, 2010.

Holmkvist, L., Ferdelman, TG and Jørgensen, BB: A cryptic sulfur cycle driven by iron in the methane zone of marine sediment (Aarhus Bay, Denmark), Geochim Cosmochim Acta, 75, 3581-3599, https://doi.org/10.1016/j.gca.2011.03.033. 2011.

Huerta-Cepas, J., Szklarczyk, D., Forslund, K., Cook, H., Heller, D., Walter, M.C., Rattei, T., Mende, D.R., Sunagawa, S., Kuhn, M. and Jensen, L.J: eggNOG 4.5: a hierarchical orthology framework with improved functional annotations for eukaryotic, prokaryotic and viral sequences, Nucleic Acids Res, 44, D286-D293, 2016.

Jørgensen, BB: A thiosulfate shunt in the sulfur cycle of marine sediments, Sci, 249, 152-154, https://doi:10.1126/science.249.4965.152, 1990.

Jørgensen, BB and Bak, F: Pathways and microbiology of thiosulfate transformations and sulfate reduction in a marine sediment (Kattegat, Denmark), Appl Environ Microbiol, 57, 847-856, 1991.

Kaprálek, F: The physiological role of tetrathionate respiration in growing Citrobacter, Microbiology, 71, 133-139, https://doi: 10.1099/00221287-71-1-133. 1972.

Kelly, DP and Wood, AP: Reclassification of some species of Thiobacillus to the newly designated genera Acidithiobacillus gen. nov., Halothiobacillus gen. nov. and Thermithiobacillus gen. nov, Int J Syst Evol Microbiol 50, 511-516, https://doi:10.1099/00207713-50-2-511, 2000.

Kanao, T., Kamimura, K. and Sugio, T.: Identification of a gene encoding a tetrathionate hydrolase in Acidithiobacillus ferrooxidans, Journal of biotechnology,132, 16-22, https://doi.org/10.1016/j.jbiotec.2007.08.030, 2007.

Kanehisa, M., Sato, Y., Kawashima, M., Furumichi, M. \& Tanabe, M: KEGG as a reference resource for gene and protein annotation, Nucleic Acids Res, 44, 457-462, 2016.

Luther, III GW: Pyrite synthesis via polysulfide compounds, Geochim Cosmochim Acta, 55, 28392849, https://doi.org/10.1016/0016-7037(91)90449-F, 1991.

Lahiri, C., Mandal, S., Ghosh, W., Dam, B and Roy, P: A novel gene cluster soxSRT is essential for the chemolithotrophic oxidation of thiosulfate and tetrathionate by Pseudaminobacter salicylatoxidans KCT001, Curr Microbiol, 52, 267-273, https://doi.org/10.1007/s00284-0050176-x, 2006.

Langmead, B., Trapnell, C., Pop, M and Salzberg, SL: Ultrafast and memory-efficient alignment of short DNA sequences to the human genome. Genome Biol, 10, 25, https://doi.org/10.1186/gb-2009-10-3-r25, 2009.

Li, D., Liu, C. M., Luo, R., Sadakane, K., Lam, T. W: MEGAHIT: an ultra-fast single-node solution for large and complex metagenomics assembly via succinct de Bruijn graph, Bioinformatics, 31, 1674-1676, https://doi.org/10.1093/bioinformatics/btv033, 2015.

Meyer, F., Paarmann, D., D'Souza, M., Olson, R., Glass, EM., Kubal, M., Paczian, T., Rodriguez, A., Stevens, R., Wilke, A and Wilkening, J: The metagenomics RAST server-a public resource for the automatic phylogenetic and functional analysis of metagenomes, BMC Bioinformatics, 9, 386, https://doi.org/10.1186/1471-2105-9-386, 2008.

Mazumdar, A., Peketi, A., Joao, H., Dewangan, P., Borole, DV and Kocherla, M: Sulfidization in a shallow coastal depositional setting: Diagenetic and palaeoclimatic implications, Chemical Geology, 322, 68-78, https://doi.org/10.1016/j.chemgeo.2012.06.005, 2012.

Mikheenko, A., Saveliev, V. and Gurevich, A: MetaQUAST: evaluation of metagenome assemblies, Bioinformatics, 32, 1088-1090, https://doi.org/10.1093/bioinformatics/btv697 2016. 
Nurk, S., Bankevich, A., Antipov, D., Gurevich, AA., Korobeynikov, A., Lapidus, A., Prjibelski, AD., Pyshkin, A., Sirotkin, A., Sirotkin, Y and Stepanauskas, R: Assembling single-cell genomes and mini-metagenomes from chimeric MDA products. J Comput Biol, 20, 714737, https://doi.org/10.1089/cmb.2013.0084, 2013.

690 Oltmann, LF and Stouthamer, $\mathrm{AH}$ : Reduction of tetrathionate, trithionate and thiosulphate, and oxidation of sulphide in Proteus mirabilis, Arch Microbiol, 105, 135-142, https://doi.org/10.1007/BF00447128, 1975.

Podgorsek, L and Imhoff, JF: Tetrathionate production by sulfur oxidizing bacteria and the role of tetrathionate in the sulfur cycle of Baltic Sea sediments, Aquat Microb Ecol, 17, 255-265, https://doi:10.3354/ame017255, 1999.

Price-Carter, M., Tingey, J., Bobik, TA and Roth, JR: The Alternative Electron Acceptor Tetrathionate Supports B12 Dependent Anaerobic Growth of Salmonella enteric Serovar Typhimurium on Ethanolamine or 1,2-Propanediol, J Bacteriol, 183, 2463-2475, https://doi: 10.1128/JB.183.8.2463-2475.2001, 2001.

700 Parte, AC: LPSN_list of prokaryotic names with standing in nomenclature. Nucleic Acids Res, 42, 613-616, https://doi.org/10.1093/nar/gkt1111, 2013.

Pyne, P., Alam, M., and Ghosh, W: A novel soxO gene, encoding a glutathione disulfide reductase, is essential for tetrathionate oxidation in Advenella kashmirensis, Microbiol Res, 205,1-7, 2017.

705 Pyne, P., Alam, M., Rameez, MJ., Mandal, S., Sar, A., Mondal, N., Debnath, U., Mathew, B., Misra, AK., Mandal, AK and Ghosh, W. Homologs from sulfur oxidation (Sox) and methanol dehydrogenation (Xox) enzyme systems collaborate to give rise to a novel pathway of chemolithotrophic tetrathionate oxidation, Mol Microbiol, 109, 169-191, https://doi.org/10.1111/mmi.13972, 2018.

710 Quast, C., Pruesse, E., Yilmaz, P., Gerken, J., Schweer, T., Yarza, P., Peplies, J and Glöckner, FO: The SILVA ribosomal RNA gene database project: improved data processing and web-based tools, Nucleic Acids Res, 41, 590-596, https://doi.org/10.1093/nar/gks1219, 2012.

Quatrini, R., Appia-Ayme, C., Denis, Y., Jedlicki, E., Holmes, D.S. and Bonnefoy, V: Extending the models for iron and sulfur oxidation in the extreme acidophile Acidithiobacillus ferrooxidans, BMC genomics, 10, 394, https://doi.org/10.1186/1471-2164-10-394, 2009.

Rowe Annette, R., Chellamuthu, P., Lam, B., Okamoto, A., and Nealson, KH: Marine sediments microbes capable of electrode oxidation as a surrogate for lithotrophic insoluble substrate metabolism, Front Microbiol, 5, 784, https://doi.org/10.3389/fmicb.2014.00784, 2015.Sass, H., Steuber, J., Kroder, M., Kroneck, PMH and Cypionka, H: Formation of thionates by freshwater and marine strains of sulfate-reducing bacteria, Arch Microbiol, 158, 418-421, https://doi.org/10.1007/BF00276302, 1992.

Rudnicki, M.D., Elderfield, H. and Spiro, B: Fractionation of sulfur isotopes during bacterial sulfate reduction in deep ocean sediments at elevated temperatures, Geochim. Cosmochim. Acta, 65, 777-789, https://doi.org/10.1016/S0016-7037(00)00579-2, 2001.

Sass H., Steuber J., Kroder M., Kroneck PMH and Cypionka H: Formation of thionates by freshwater and marine strains of sulfate-reducing bacteria, Arch Microbiol, 158, 418-421, https://doi.org/10.1007/BF00276302, 1992.

Schippers, A., Rohwerder, T and Sand, W: Intermediary sulfur compounds in pyrite oxidation: implications for bioleaching and biodepyritization of coal, Appl Microbiol Biotechnol, 52, 104-110, https://doi.org/10.1007/s002530051495, 1999.

Sievert, SM., Heidorn, T and Kuever, J: Halothiobacillus kellyi sp. nov., a mesophilic, obligately chemolithoautotrophic, sulfur-oxidizing bacterium isolated from a shallow-water hydrothermal vent in the Aegean Sea, and emended description of the genus 
Halothiobacillus. Int J Syst Evol Microbiol, 50, 1229-1237, https://doi: 10.1099/0020771350-3-1229, 2000.

Schippers, A and Jørgensen, BB: Oxidation of pyrite and iron sulfide by manganese dioxide in marine sediments, Geochim Cosmochim Acta, 65, 915-922, https://doi.org/10.1016/S0016-7037(00)00589-5, 2001.

740 Sorokin, D: Oxidation of inorganic sulfur compounds by obligatory organotrophic bacteria, Mikrobiologiia, 72, 725-739, https://doi.org/10.1023/B:MICl.0000008363.24128.e52003, 2003.

Stoffels, L., Krehenbrink, M., Berks, BC and Unden, G. Thiosulfate Reduction in Salmonella enterica Is Driven by the Proton Motive Force, Appl Environ Microbiol, 194, 475-485. https://doi:10.1128/JB.06014-11, 2011.

Sujith, PP and Bharathi, PL: Manganese oxidation by bacteria: biogeochemical aspects. In Molecular Biomineralization, 52, 49-76, https://doi.org/10.1007/978-3-642-21230-73, 2011.

Tuttle, JH: Thiosulfate oxidation and tetrathionate reduction by intact cells of marine pseudomonad strain 16B, Appl Environ Microbiol, 39, 1159-1166, 1980.

Thamdrup, B., Finster, K., Fossing, H., Hansen, JW \& Jørgensen, BB: Thiosulfate and sulfite distributions in porewater of marine sediments related to manganese, iron, and sulfur geochemistry, Geochim Cosmochim Acta, 58, 67-73, https://doi:1016/00167037(94)90446-4, 1994.

Tebo, B.M., Johnson, H.A., McCarthy, J.K. and Templeton, A.S: Geomicrobiology of manganese (II) oxidation, Trends Microbiol, 13, 421-428, https://doi.org/10.1016/j.tim.2005.07.009, 2005.

Tostevin, R., Turchyn, A.V., Farquhar, J., Johnston, D.T., Eldridge, D.L., Bishop, J.K. and Mcllvin, M: Multiple sulfur isotope constraints on the modern sulfur cycle, Earth Planet Sci Lett, 396, 14-21, https://doi.org/10.1016/j.epsl.2014.03.057, 2014.

760 Vishniac, W and Santer, M: The thiobacilli. Bacteriol Rev, 21, 195-213, 1957.

Vassiliadis, P: The Rappaport-Vassiliadis (RV) enrichment medium for the isolation of salmonellas: An overview, J Appl Bacteriol, 54, 69-76, https://doi.org/10.1111/j.13652672.1983.tb01302.x, 1983.

Zhu, W., Lomsadze, A. and Borodovsky, M: Ab initio gene identification in metagenomic sequences. Nucleic Acids Res, 38, 132-e132, https://doi.org/10.1093/nar/gkq275, 2010.

\section{Legend of figures}

Figure 1. Scatter plots showing the down-depth variations in the prevalence of key metabolic-types, or the pair-wise associations between the prevalence of the metabolic-

770 types, along SSK42/5. Parameters considered include (i) sediment-depth (in cmbsf), and percentages of metagenomic reads matching sequences from the genera of (ii) manganesedepositing, (iii) manganese-oxidizing, (iv) tetrathionate-reducing, (vi) tetrathionate-forming and (vii) tetrathionate-oxidizing bacteria. Plots corroborated by Pearson correlation coefficient (CC) and/or Spearman rank correlation coefficient (RCC) values $\geq+0.8$ with $P<0.05$ are shown in 775 blue. Whereas none of the plots were corroborated by negative CC or RCC values numerically $\geq$ 0.8 with $\mathrm{P}<0.05$, those corroborated by positive/negative $\mathrm{CC}$ and/or RCC values numerically $\leq$ 
0.8 are shown in black, irrespective of whether $P$ is $<0.05$. All CC and RCC values pertaining to the above plots are given in Table S6.

780 Figure 2. Scatter plots showing the down-depth variations in the prevalence of key metabolic-types, or the pair-wise associations between the prevalence of the metabolictypes, along SSK42/6. Parameters considered include (i) sediment-depth (in cmbsf), and percentages of metagenomic reads matching sequences from the genera of (ii) manganesedepositing, (iii) manganese-oxidizing, (iv) tetrathionate-reducing, (vi) tetrathionate-forming and 785 (vii) tetrathionate-oxidizing bacteria. Plots corroborated by Pearson correlation coefficient (CC) and/or Spearman rank correlation coefficient (RCC) values $\geq+0.8$ with $P<0.05$ are shown in blue. Whereas none of the plots were corroborated by negative CC or RCC values numerically $\geq$ 0.8 with $\mathrm{P}<0.05$, those corroborated by positive/negative $\mathrm{CC}$ and/or RCC values numerically $\leq$ 0.8 are shown in black, irrespective of whether $P$ is $<0.05$. All CC and RCC values pertaining to 790 the above plots are given in Table S7.

Figure 3. Metabolic transformations of thiosulfate and/or tetrathionate by representative strains of the various species-level entities isolated from $275 \mathrm{cmbsf}$ of SSK42/6. (A through D) thiosulfate to tetrathionate conversion by Halomonas sp 15WGF, Methylophaga sp. SBPC3, 795 Pseudomonas sp. SBBB and Stenotrophomonas sp. SBPC3 respectively. (E and $\mathbf{F}$ ) thiosulfate to tetrathionate conversion and tetrathionate oxidation to sulfate by Pusillimonas sp. SBSA respectively. (G) tetrathionate oxidation to sulfate by Halothiobacillus sp. SB14A. (H) tetrathionate reduction to thiosulfate by Enterobacter sp. RVSM5a.

- •-, $\boldsymbol{-} \mathbf{\Delta}-$ and $-\boldsymbol{\nabla}-$ and denote the concentration of sulfur (mM S) in the spent media, at 800 any time-point of incubation in the form of thiosulfate, sulfate and tetrathionate respectively.

- - denotes the $\mathrm{pH}$ of the spent medium at any given time point of incubation.

Figure 4. Schematic diagram showing the network of biotic and abiotic process that are potentially involved in the formation and transformation of tetrathionate in the Arabian Sea OMZ sediments. 
Table 1. Concentrations of sulfate ${ }^{1}$, sulfide ${ }^{1}$, pyrite, iron ${ }^{2}$, manganese ${ }^{2}$ and thiosulfate in the individual sample-sites of SSK42/5 and SSK42/6.

\begin{tabular}{|c|c|c|c|c|c|c|c|c|c|c|c|c|c|}
\hline \multirow{2}{*}{$\begin{array}{l}\text { Sediment- } \\
\text { depth } \\
\text { (cmbsf) }\end{array}$} & \multicolumn{6}{|c|}{ SSK42/5 } & \multirow{2}{*}{$\begin{array}{l}\text { Sediment- } \\
\text { depth } \\
\text { (cmbsf) }\end{array}$} & \multicolumn{6}{|c|}{ SSK42/6 } \\
\hline & $\begin{array}{c}\text { Sulfate } \\
(\mathrm{mM})\end{array}$ & $\begin{array}{c}\text { Sulfide } \\
(\mu \mathrm{M})\end{array}$ & $\begin{array}{l}\begin{array}{l}\text { Pyrite } \\
(\text { wt \%) }\end{array} \\
\end{array}$ & $\begin{array}{l}\begin{array}{l}\text { Iron } \\
(\mathrm{ppm})\end{array} \\
\end{array}$ & $\begin{array}{c}\text { Manganese } \\
(\mathrm{ppm})\end{array}$ & $\begin{array}{c}\text { Thiosulfate } \\
(\mu \mathrm{M})\end{array}$ & & $\begin{array}{c}\text { Sulfate } \\
(\mathrm{mM})\end{array}$ & $\begin{array}{c}\text { Sulfide } \\
(\mu \mathrm{M})\end{array}$ & $\begin{array}{l}\text { Pyrite } \\
\text { (wt \%) }\end{array}$ & $\begin{array}{c}\text { Iron } \\
\text { (ppm) }\end{array}$ & $\begin{array}{c}\text { Manganese } \\
(\text { ppm) }\end{array}$ & $\begin{array}{c}\text { Thiosulfate } \\
(\mu \mathrm{M})\end{array}$ \\
\hline 1 & 28.8356 & 62.0819 & 0.05 & 9847 & 78.1 & 0.98 & 1 & 27.6718 & 0 & 0.11 & 9302 & 87.7 & 0 \\
\hline 15 & 27.9356 & 57.264 & 0.06 & 13158 & 83.07 & 0.99 & 15 & 25.4969 & 0 & 0.06 & - & - & 0 \\
\hline 30 & 25.7704 & 59.3288 & 0.28 & - & - & - & 30 & 26.6722 & 321.3249 & 0.14 & - & - & 2.5 \\
\hline 45 & 23.1922 & 61.3936 & 0.47 & - & - & 0.99 & 45 & 23.1086 & 603.253 & 0.37 & - & - & 5.2 \\
\hline 60 & 22.4571 & 99.2484 & 0.46 & - & - & 1.5 & 60 & 20.8097 & 586.3688 & 0.75 & - & - & 4.7 \\
\hline 75 & 19.7155 & 194.2296 & 0.57 & - & - & - & 75 & 18.829 & 710.1869 & 0.90 & - & - & - \\
\hline 90 & 17.2669 & 313.3001 & 0.68 & - & - & 4.2 & 90 & 17.2731 & 1070.385 & 0.64 & 9374 & 71.1 & 8.2 \\
\hline 105 & 17.6498 & 427.0022 & 0.60 & - & - & - & 105 & 16.4295 & 507.5754 & 1.02 & - & - & - \\
\hline 120 & 16.2797 & 226.5782 & 0.70 & 9574 & 74.3 & 4.0 & 120 & 15.3848 & 772.0959 & 1.09 & 10722 & 77.1 & 7.5 \\
\hline 135 & 15.8326 & 254.9349 & 0.57 & - & - & - & 135 & 14.4313 & 704.5588 & 0.58 & 12312 & 105 & 7 \\
\hline 145 & 14.7989 & 296.7817 & 0.58 & 9842 & 87.1 & 3.1 & 145 & 13.4006 & 1172.7375 & 0.66 & - & - & - \\
\hline 175 & 13.0084 & 183.9055 & 0.61 & - & - & - & 175 & 10.1722 & 1071.4318 & 0.62 & - & - & 8.1 \\
\hline 190 & 11.043 & 154.3099 & 0.75 & - & - & 3.2 & 190 & 9.296 & 947.6137 & 0.29 & - & - & - \\
\hline 205 & 10.5552 & 203.8653 & 0.83 & - & - & - & 205 & 7.4672 & 1341.5804 & 0.39 & - & - & - \\
\hline 220 & 9.6447 & 61.3936 & 0.74 & - & - & 1.1 & 220 & 5.6191 & 1274.0432 & 0.59 & - & - & 11.1 \\
\hline 235 & 8.3577 & 54.5109 & 0.49 & - & - & - & 235 & 4.1801 & 1240.2747 & 0.32 & - & - & - \\
\hline 250 & 6.6526 & 58.6405 & 0.50 & 17234 & 171.9 & 1.2 & 250 & 2.0497 & 2010.2769 & 0.45 & - & - & - \\
\hline 280 & 4.3842 & 54.5109 & 0.86 & - & - & - & 265 & 0.8708 & 970.1261 & 0.49 & 9232 & 105 & 6.8 \\
\hline \multirow[t]{2}{*}{295} & 7.46 & 51.7578 & 0.80 & 12329 & 147.2 & 1.1 & 280 & 0.2806 & 1217.7623 & 0.38 & 10359 & 116.9 & 5.5 \\
\hline & & & & & & & 295 & 0.4786 & 1116.4566 & 0.70 & - & - & - \\
\hline
\end{tabular}

1 Data for pore-water sulfate and sulfide concentrations were taken from Fernandes et al. (2018); values for all the other chemical concentrations were determined in this study.

2 Concentrations given for iron and manganese were determined for bulk sediment-samples, which included both the solid-phases and porewaters; all other concentrations given are for pore-waters extracted from individual sediment-samples. 
Table 2. Bacteria isolated from $275 \mathrm{cmbsf}$ of SSK42/6, and their tetrathionate-metabolizing properties.

\begin{tabular}{|c|c|c|c|c|c|c|c|}
\hline \multirow[b]{2}{*}{$\begin{array}{l}\text { Identification up to } \\
\text { lowest taxonomic } \\
\text { level possible }\end{array}$} & \multicolumn{2}{|c|}{$\begin{array}{l}\text { Bacteria isolated } \\
\text { in ASWT }\end{array}$} & \multirow{2}{*}{$\begin{array}{c}\begin{array}{c}\text { Bacteria } \\
\text { isolated } \\
\text { in ASWTY }\end{array} \\
\text { Halomonas } \\
\text { sp. }\end{array}$} & \multicolumn{3}{|c|}{ Bacteria isolated in MSTY } & \multirow{2}{*}{$\begin{array}{c}\begin{array}{c}\text { Bacteria } \\
\text { isolated } \\
\text { in RVTr }\end{array} \\
\text { Enterobacter sp. }\end{array}$} \\
\hline & $\begin{array}{l}\text { Halothiobacillus } \\
\text { sp. }\end{array}$ & $\begin{array}{l}\text { Methylophaga } \\
\text { sp. }\end{array}$ & & $\begin{array}{c}\text { Pseudomonas } \\
\text { sp }\end{array}$ & $\begin{array}{c}\text { Stenotrophomonas } \\
\text { sp. }\end{array}$ & $\begin{array}{l}\text { Pusillimonas } \\
\text { ginsengisoli }\end{array}$ & \\
\hline $\begin{array}{llr}\text { Total } & \text { number of } \\
\text { strains } & \text { isolated for } \\
\text { the } & \text { species-level } \\
\text { cluster } & \\
\end{array}$ & 6 & 2 & 2 & 2 & 1 & 2 & 4 \\
\hline $\begin{array}{l}\text { Name of the } \\
\text { representative strain }\end{array}$ & SB14A & $\begin{array}{c}\text { SB9B } \\
= \\
\text { MTCC12599 }\end{array}$ & $\begin{array}{c}\text { 15WGF } \\
= \\
\text { MCC3301 }\end{array}$ & $\begin{array}{c}\text { SBBB } \\
= \\
\text { MTCC12600 }\end{array}$ & SBPC3 & $\begin{array}{c}\text { SBSA } \\
= \\
\text { MTCC12558 }\end{array}$ & RVSM5a \\
\hline $\begin{array}{l}\text { 16S rRNA gene } \\
\text { sequence accession } \\
\text { number of the } \\
\text { representative strain }\end{array}$ & LN999387 & LN999390 & LT607031 & LN999396 & LN999400 & LN999398 & MH593841 \\
\hline $\begin{array}{l}\text { Tetrathionate- } \\
\text { metabolizing } \\
\text { phenotype (medium } \\
\text { in which phenotype } \\
\text { was tested) }\end{array}$ & $\begin{array}{l}\text { (i) Tetrathionate } \\
\text { to sulfate } \\
\text { (ASWTr) }\end{array}$ & $\begin{array}{l}\text { (i) Thiosulfate } \\
\text { to } \\
\text { tetrathionate } \\
\text { (ASWTM) }\end{array}$ & $\begin{array}{l}\text { (i) Thiosulfate } \\
\text { to } \\
\text { tetrathionate } \\
\text { (ASWTY) }\end{array}$ & $\begin{array}{l}\text { (i) Thiosulfate } \\
\text { to tetrathionate } \\
\text { (MSTY) }\end{array}$ & $\begin{array}{l}\text { (i) Thiosulfate to } \\
\text { tetrathionate } \\
\text { (MSTY) }\end{array}$ & $\begin{array}{l}\text { (i) Thiosulfate to } \\
\text { tetrathionate } \\
\text { (MSTY) } \\
\text { (ii) Tetrathionate } \\
\text { to sulfate } \\
\text { (MSTrY) }\end{array}$ & $\begin{array}{l}\text { (i) Tetrathionate } \\
\text { to thiosulfate } \\
\text { (RVTr) }\end{array}$ \\
\hline
\end{tabular}



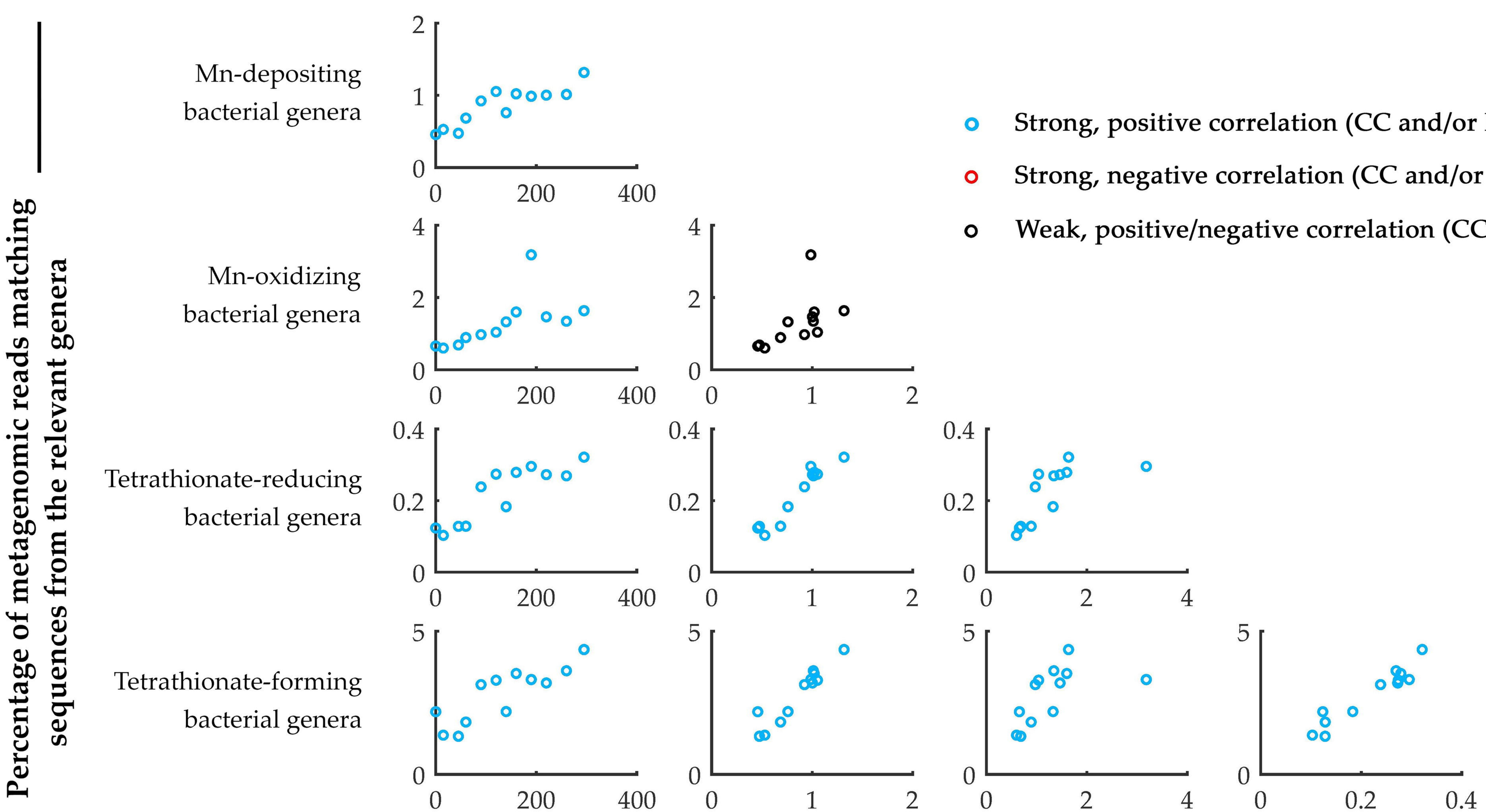

Tetrathionate-oxidizing
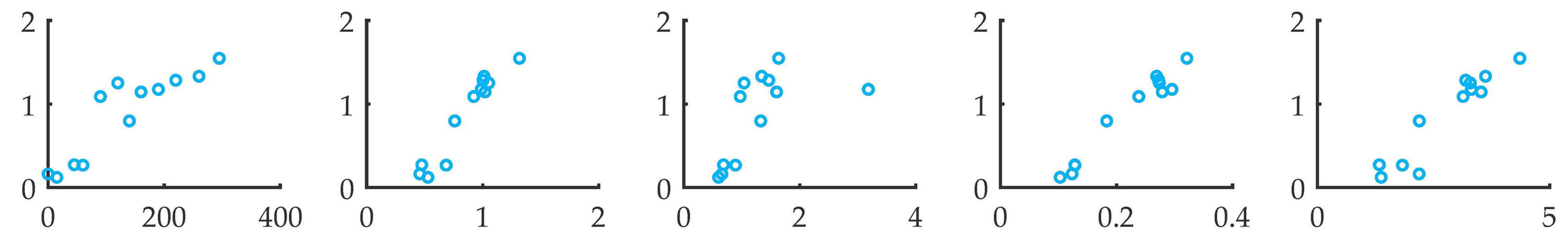

Sediment-depth (cmbsf)

Mn-depositing bacterial genera

Mn-oxidizing bacterial genera
Tetrathionate-reducing Tetrathionate-forming bacterial genera bacterial genera

Percentage of metagenomic reads matching sequences from the relevant genera 
Mn-depositing bacterial genera

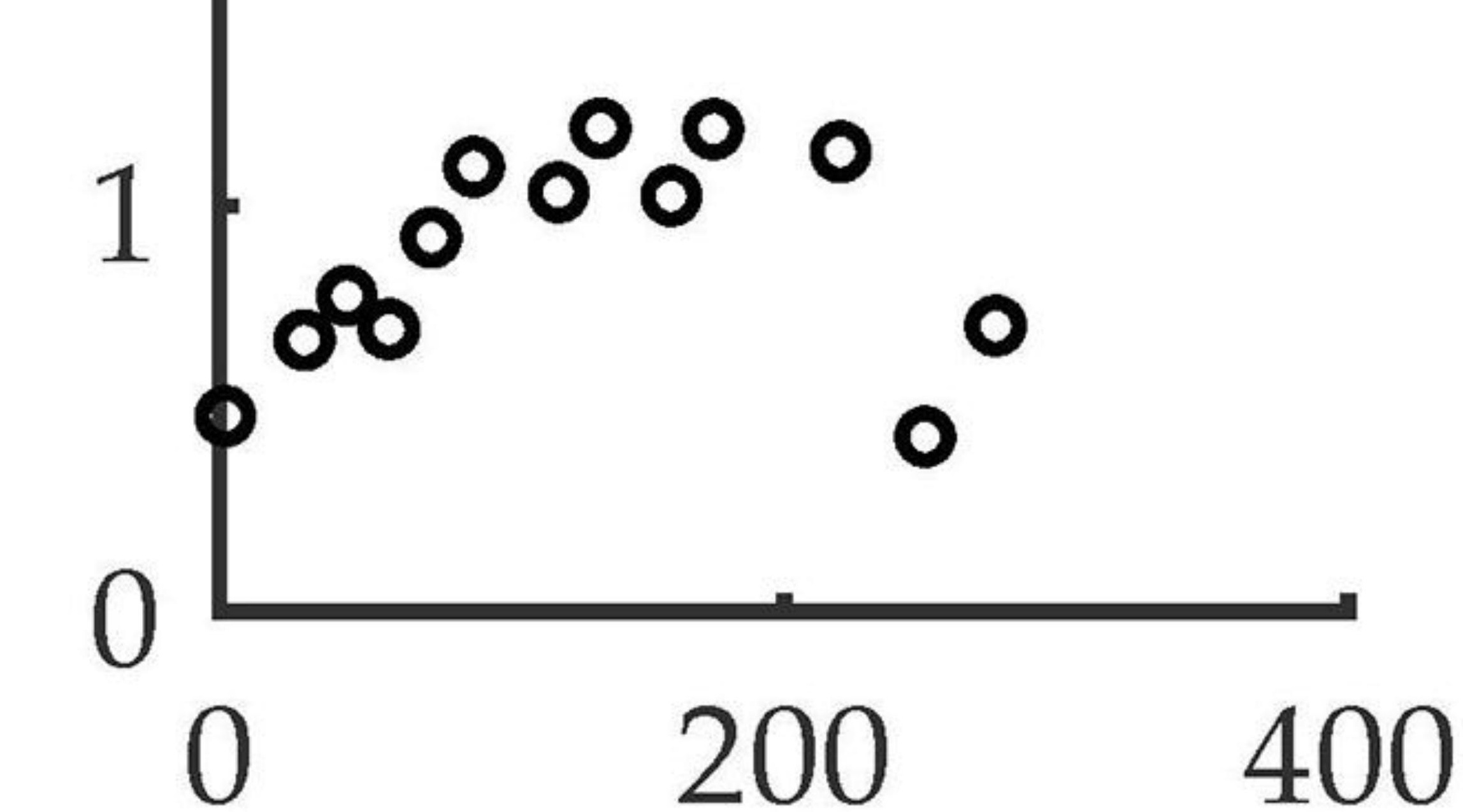

Mn-oxidizing bacterial genera
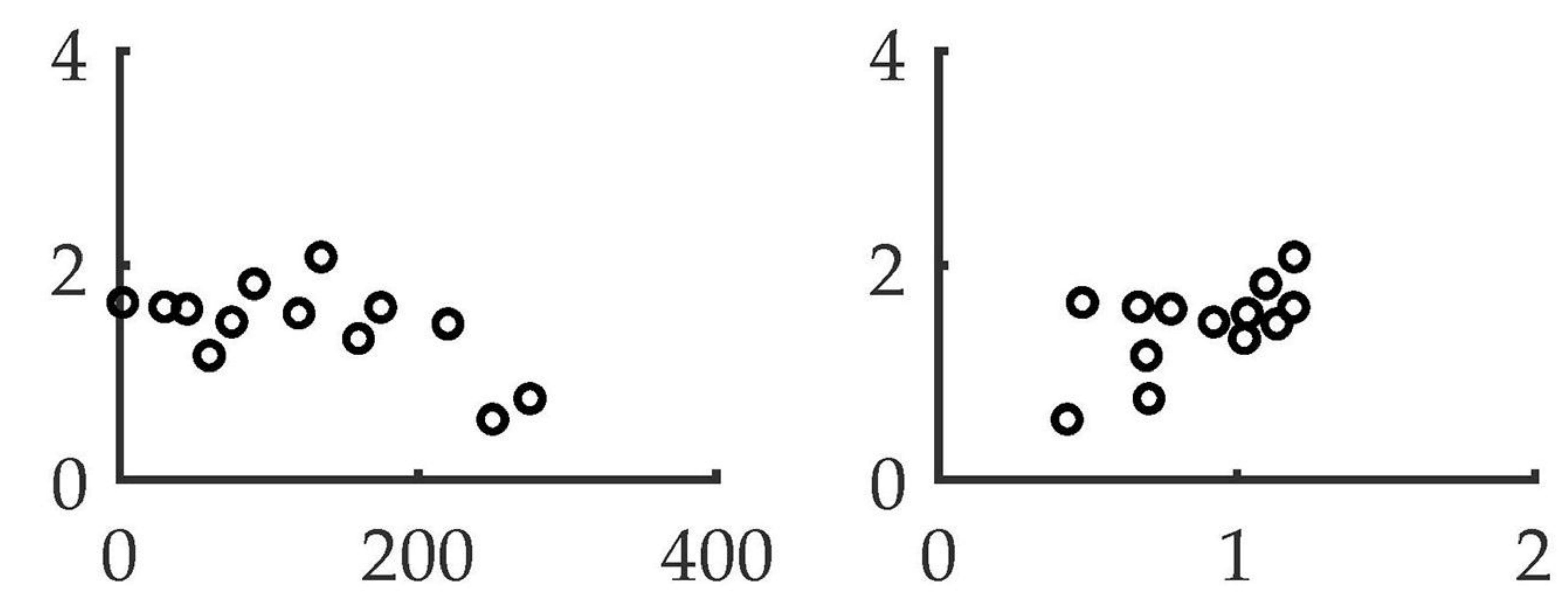

Tetrathionate-reducing bacterial genera
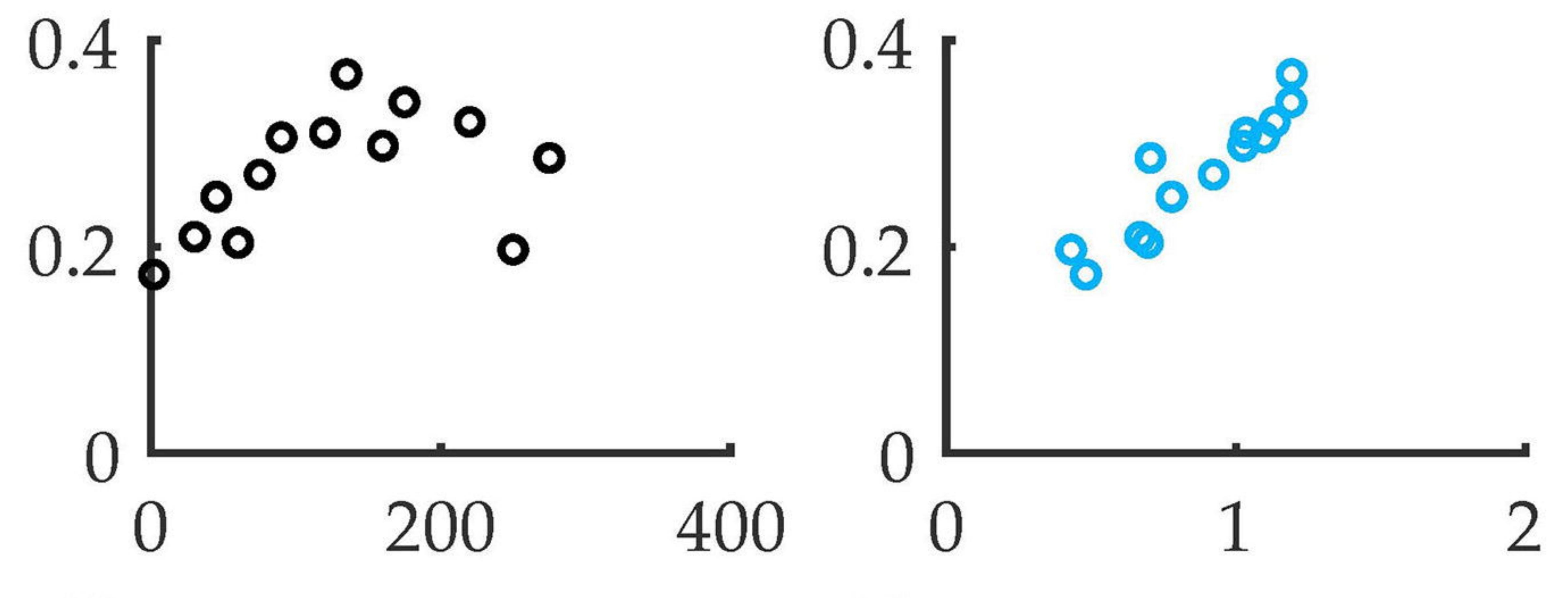

Tetrathionate-forming bacterial genera

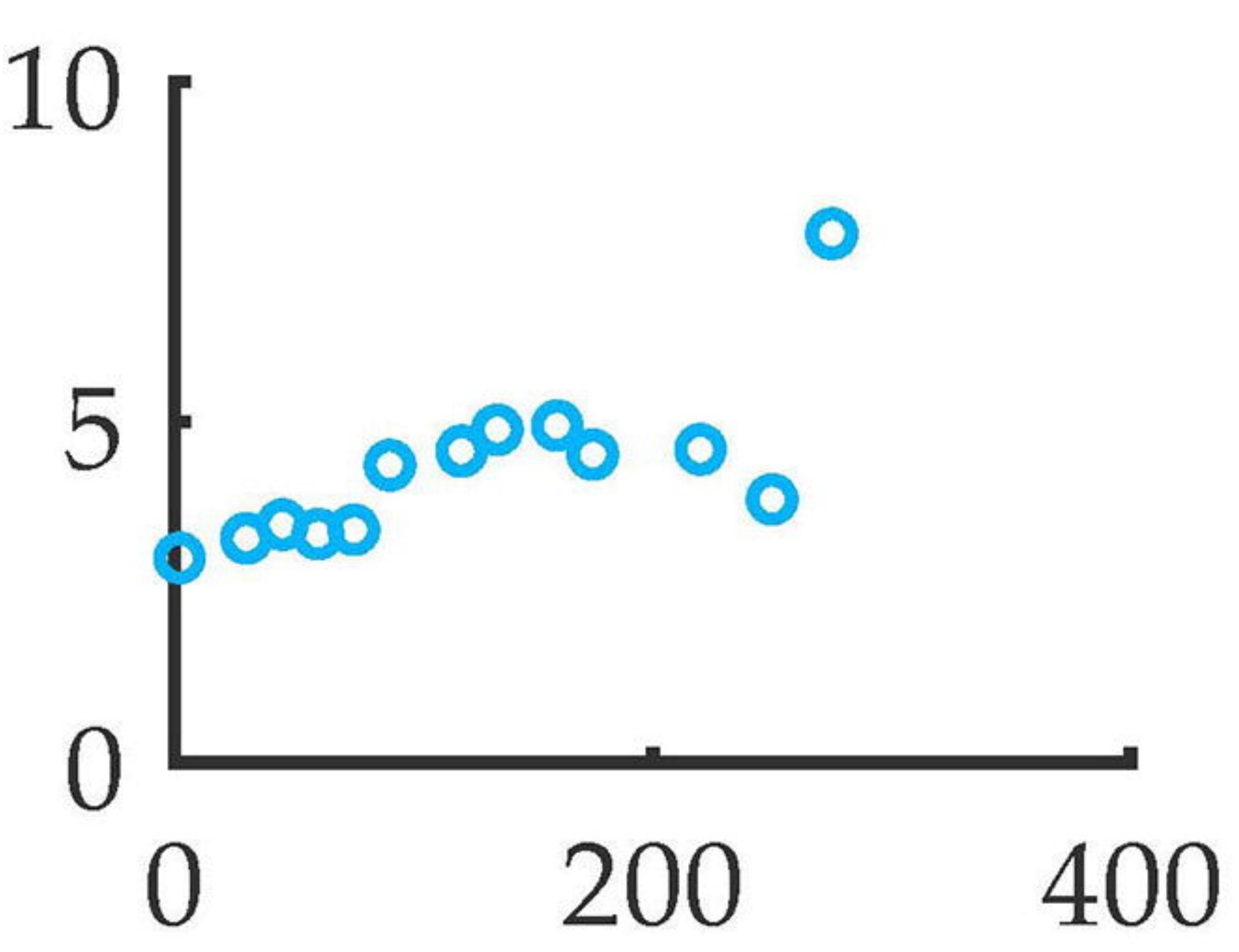

Tetrathionate-oxidizing bacterial genera

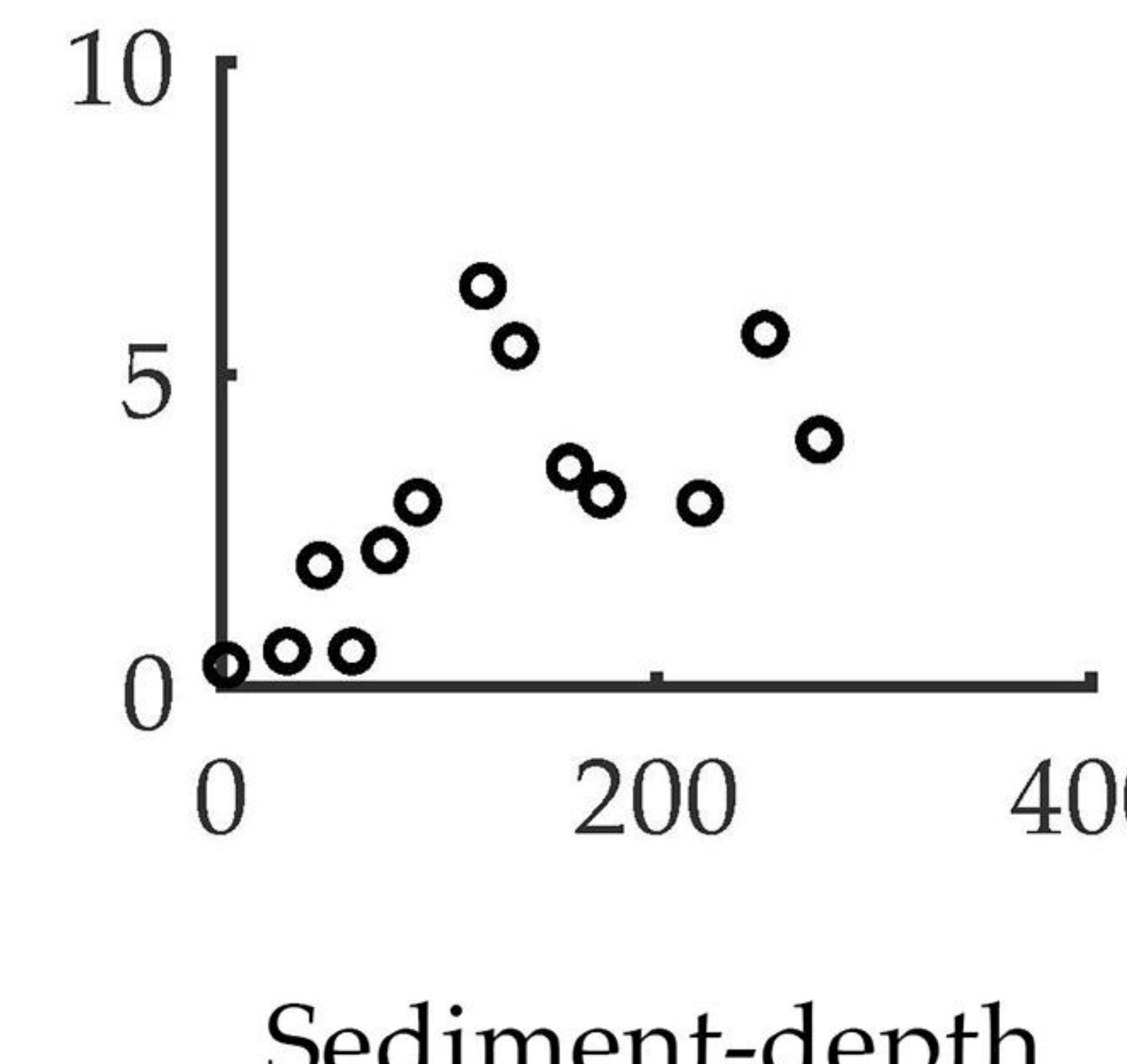

(cmbsf)
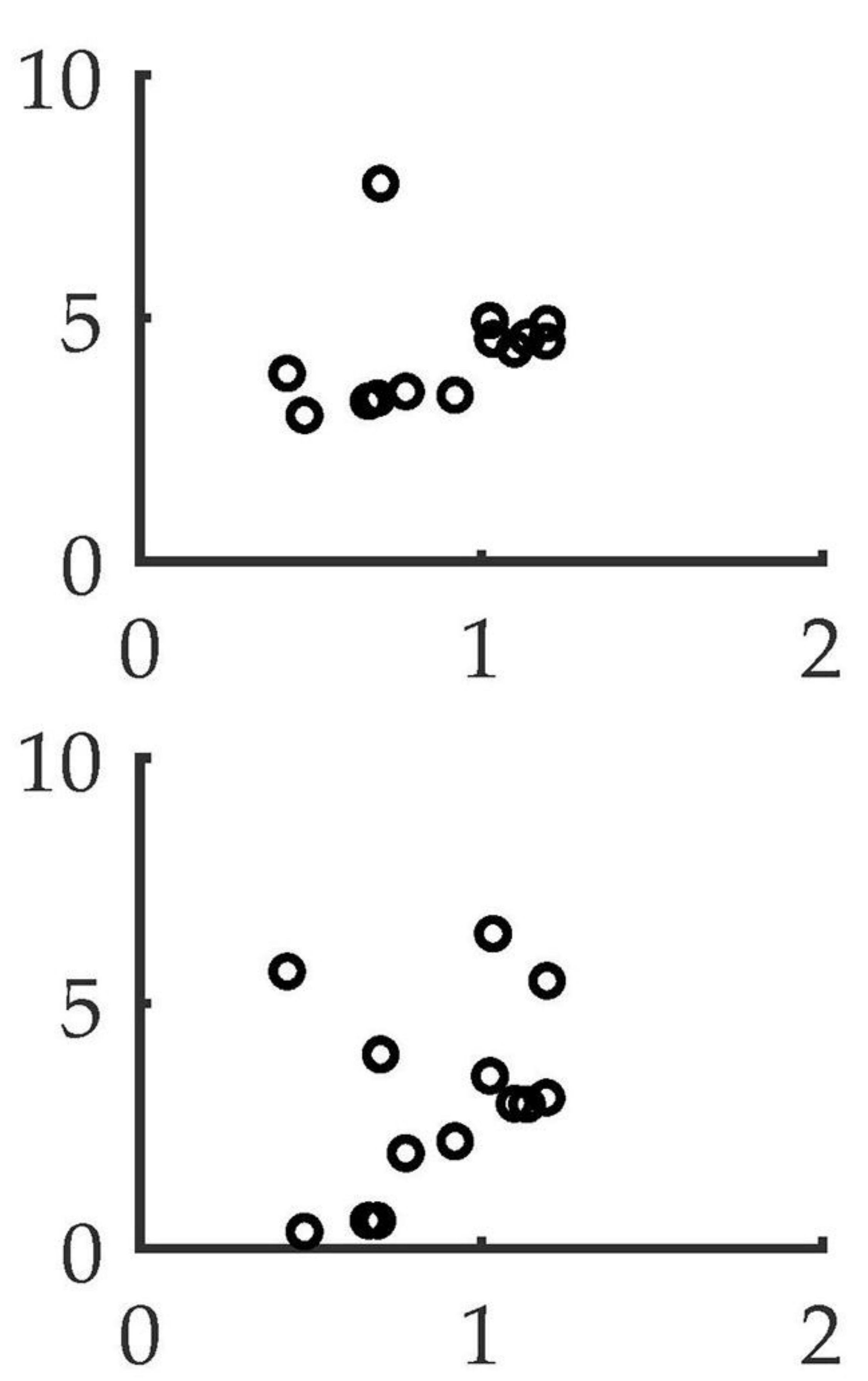

Mn-depositing bacterial genera
- Strong, positive correlation (CC and/or RCC)

- Strong, negative correlation (CC and/or RCC)

- Weak, positive/negative correlation (CC and/or RCC)
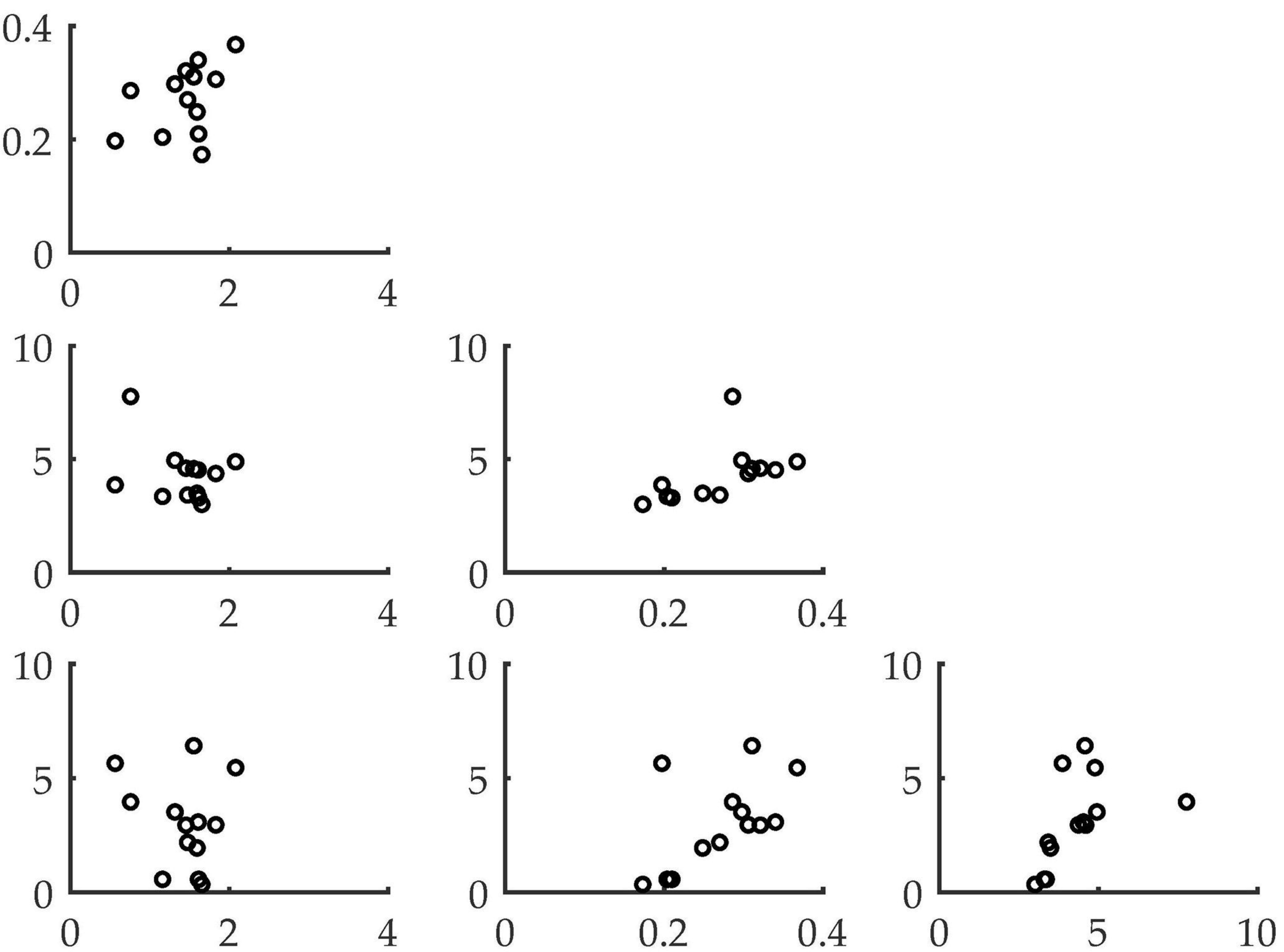

Mn-oxidizing

Tetrathionate-reducing Tetrathionate-forming bacterial genera bacterial genera

Percentage of metagenomic reads matching sequences from the relevant genera 


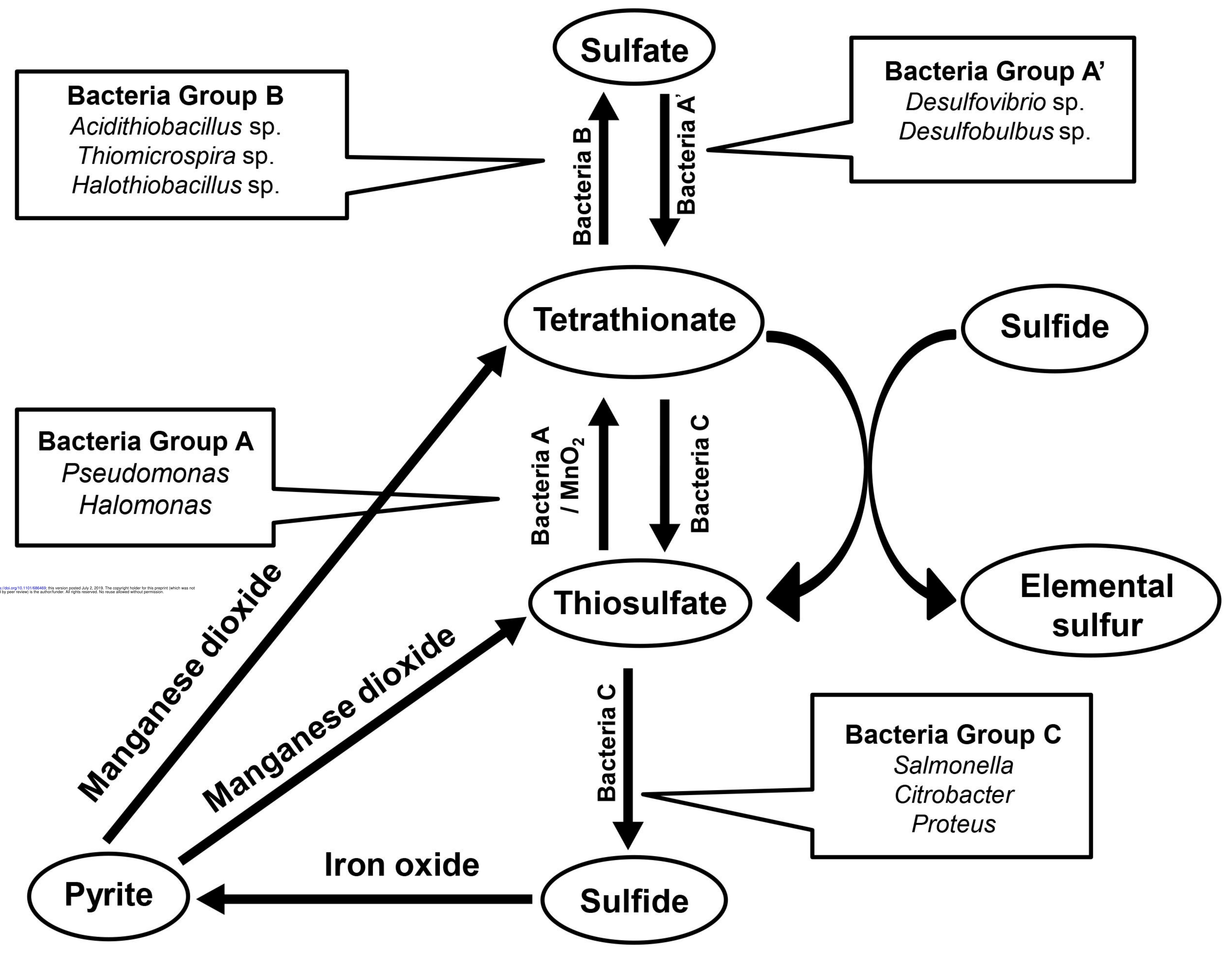

